\title{
The Glycosylphosphatidylinositol Anchor Biosynthesis Genes GPI12, GAA1, and GPI8 Are Essential for Cell-Wall Integrity and Pathogenicity of the Maize Anthracnose Fungus Colletotrichum graminicola
}

\author{
Ely Oliveira-Garcia ${ }^{1}$ and Holger B. Deising ${ }^{1,2}$ \\ ${ }^{1}$ Martin-Luther-Universität Halle-Wittenberg, Naturwissenschaftliche Fakultät III, Institut für Agrar- und Ernährungswissenschaften, \\ Phytopathologie und Pflanzenschutz, and ${ }^{2}$ Interdisziplinäres Zentrum für Nutzpflanzenforschung; Betty-Heimann-Str. 3. D-06120 \\ Halle/Saale, Germany
}

Accepted 26 October 2016.

\begin{abstract}
Glycosylphosphatidylinositol (GPI) anchoring of proteins is one of the most common posttranslational modifications of proteins in eukaryotic cells and is important for associating proteins with the cell surface. In fungi, GPI-anchored proteins play essential roles in cross-linking of $\beta$-glucan cell-wall polymers and cell-wall rigidity. GPI-anchor synthesis is successively performed at the cytoplasmic and the luminal face of the ER membrane and involves approximately 25 proteins. While mutagenesis of auxiliary genes of this pathway suggested roles of GPI-anchored proteins in hyphal growth and virulence, essential genes of this pathway have not been characterized. Taking advantage of RNA interference (RNAi) we analyzed the function of the three essential genes GPI12, GAA1 and $G P I 8$, encoding a cytoplasmic $N$-acetylglucosaminylphosphatidylinositol deacetylase, a metallo-peptide-synthetase and a cystein protease, the latter two representing catalytic components of the GPI transamidase complex. RNAi strains showed drastic cell-wall defects, resulting in exploding infection cells on the plant surface and severe distortion of in planta-differentiated infection hyphae, including formation of intrahyphal hyphae. Reduction of transcript abundance of the genes analyzed resulted in nonpathogenicity. We show here for the first time that the GPI synthesis genes GPI12, GAA1, and GPI8 are indispensable for vegetative development and pathogenicity of the causal agent of maize anthracnose, Colletotrichum graminicola.
\end{abstract}

Glycosylphosphatidylinositols (GPI) are structurally complex glycolipids, which are posttranslationally added to the C-terminus of secretory proteins. Covalent attachment of GPI to the C-terminus is one of the most common posttranslational modifications of proteins in eukaryotic cells and important for anchoring of proteins to the cell surface (Yu et al. 2013). Synthesis of GPI and its subsequent transfer to proteins has

Current address for E. Oliveira-Garcia: Kansas State University, Department of Plant Pathology, Manhattan, KS, U.S.A.

Corresponding author: H. B. Deising;

E-mail: holger.deising@landw.uni-halle.de

*The $\boldsymbol{e}$-Xtra logo stands for "electronic extra" and indicates that one supplementary figure and one supplementary table are published online.

(C) 2016 The American Phytopathological Society been extensively studied in the model yeast Saccharomyces cerevisiae, the causal agent of the African sleeping sickness Trypanosoma brucei and in man. GPI synthesis and fusion of the anchor with proteins are executed by approximately 25 proteins, take place successively on the cytoplasmic and on the luminal face of the membrane of the endoplasmic reticulum (ER), and are highly conserved across the eukaryotic kingdoms (Fig. 1) (Pittet and Conzelmann 2007).

The first step of GPI synthesis is the addition of $N$-acetyl glucosamine to phosphatidylinositol. This reaction occurs on the cytoplasmic ER surface and is catalyzed by $\mathrm{N}$-acetyl glucosaminyl transferase, an unusually complex glycosyl transferase consisting of six core proteins, i.e., Gpi1, Gpi2, Gpi3, Gpi15, Eri1, and Gpi19. The acetyl group of the $N$-acetyl glucosaminyl residue is subsequently removed by the cytoplasmic $N$-acetylglucosaminylphosphatidylinositol deacetylase encoded by GPII2 (Fig. 1), and the inositol ring is then enzymatically $O$-acylated at the $\mathrm{C} 2$ by the inositol acyltransferase Gwt1. In yeast and man, inositol acylation has been reported mainly as palmitoylation, and the substrate specificity of Gwt1 was shown to be responsible for the acyl residue attached (Umemura et al. 2003). The resulting intermediate is translocated to the luminal side of the phospholipid bilayer. In the ER lumen, two mannosyl units are subsequently linked to the glucosamine by the two distinct ER-resident dolichol phosphate mannose:glucosaminyl phosphatidylinositol $\alpha-1,4$-mannosyltransferases Gpi14 and Gpi18. Interestingly, analysis of the substrate specificity of the first mannosyltransferase of the GPI synthesis pathway in African trypanosomes showed that $N$-acetylglucosaminylphosphatidylinositol is a more efficient substrate for this enzyme than its deacetylated form, suggesting a substrate channelling function of the preceeding Gpi12 (Smith et al. 1996). Next, the addition of the first phosphoryl-ethanolamine residue to the first mannosyl unit is catalyzed by Mcd4. The phosphoryl-ethanolamine group linked to the first mannosyl residue is required for recognition of the GPI and addition of the third mannosyl group by the mannosyltransferase Gpi10. The addition of a fourth onto the third mannosyl residue by Smp3 is required for adding the second phosphoethanolamine group to the third mannosyl residue, as catalyzed by Gpi13. The last step of GPI biosynthesis before attaching this anchor to a protein is the addition of a third phosphoryl-ethanolamine residue to the second mannosyl residue, as mediated by ethanolamine phosphotransferase Gpi7.

The attachment of GPI to the C-terminus of a protein is catalyzed by the GPI transamidase complex, consisting of the 
five distinct subunits Gaa1, Gpi8, Gpi16, Gab1, and Gpi17 (Pittet and Conzelmann 2007) (Fig. 1). Integrating protein complex purification, protein interaction, and structural modeling data (Eisenhaber et al. 2003; Fraering et al. 2001; Vainauskas et al. 2002), Grimme and coworkers (2004) suggested a model for possible relationships between the subunits of the GPI transamidase, with Gpi8 as the central part interacting with Gaal and with all other proteins of the complex. Enzyme activity assays with trypanosomal recombinant Gpi8 showed cleavage of the synthetic peptide acetyl-S-V-L-N-aminomethyl-coumarine, indicating that Gpi8 is directly involved in the proteolytic processing of the GPI-anchoring signal at the C-terminus of the protein (Kang et al. 2002). Intriguingly, evidence from recent sequence analyses further indicated that the luminal domain of Gaa1 has a three-dimensional structure similar to that of an M28 family-type metallo-peptide synthetase, strongly suggesting that this enzyme catalyzes the formation

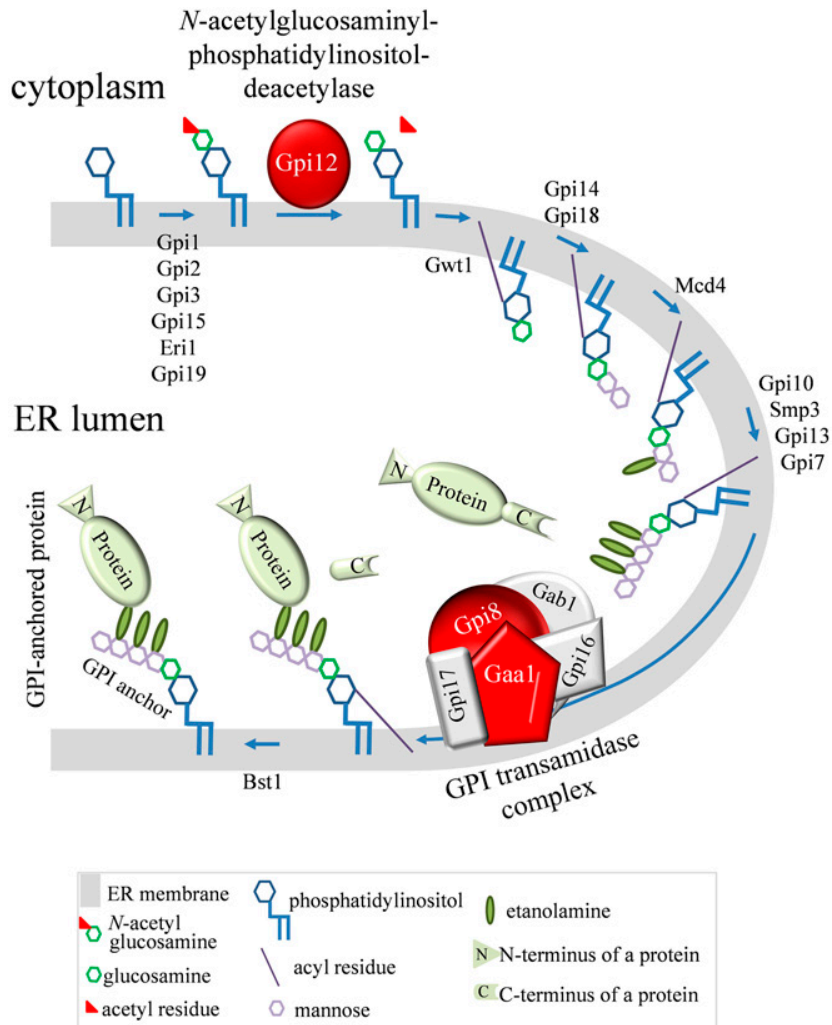

Fig. 1. Synthesis of glycosylphosphatidylinositol (GPI)-anchored proteins at the cytoplasmic and the luminal face of the endoplasmic reticulum (ER) membrane. GPI synthesis is initiated by adding $N$-acetyl glucosamine to phosphatidylinositol on the cytoplasmic ER surface, as catalyzed by $N$-acetyl glucosaminyl transferase, consisting of the six proteins Gpi1, Gpi2, Gpi3, Gpi15, Eri1, and Gpi19. The acetyl group of the $N$-acetyl glucosaminyl residue is then removed by the cytoplasmic $N$-acetylglucosaminylphosphatidylinositol deacetylase Gpi12. The inositol ring is subsequently $O$-acylated by the inositol aclytransferase Gwt1, and the resulting intermediate is translocated to the luminal side of the ER. Here, the $\alpha-1,4$ mannosyltransferases Gpi14 and Gpi18 add two mannosyl units to the glucosamine. Next, the first phosphoryl-ethanolamine residue is added to the first mannosyl unit by Mcd4 and the third and fourth mannosyl group is added by mannosyl transferases Gpi10 and Smp3. The second phosphoethanolamine group is added to the third mannosyl residue by Gpi13, and finally, a third phosphoethanolamine residue is added to the second mannosyl residue by ethanolamine phosphotransferase Gpi7. The attachment of GPI to the C-terminus of a protein is catalyzed by the GPI transamidase complex, consisting of the five distinct subunits Gpi8, Gaa1, Gpi16, Gab1, and Gpi17. Finally, the acyl chain is removed by the inositol deacylase Bst1, generating the final GPI-anchored protein. Proteins characterized in this work, i.e., Gpi12, Gaa1, and Gpi8, are shown in red. of the peptide bond between the $\omega$ site of a protein and a phosphoethanolamine group of the GPI lipid anchor (Eisenhaber et al. 2014). Finally, the acyl chain is removed by the inositol deacylase Bst1 shortly after the addition of a protein to the GPI by the transamidase complex (Pittet and Conzelmann 2007) (Fig. 1).

In $S$. cerevisiae, between 60 and 70 proteins have been estimated to be GPI-anchored (Caro et al. 1997; Pittet and Conzelmann 2007), with half of these residing in the cell wall (Levin 2011; Smits et al. 1999). Structural analyses have shown that cell-wall proteins are tightly linked to $\beta-1,6$-glucan through a remnant of a GPI anchor containing $\alpha$-linked mannosyl residues (Kollár et al. 1997). Thus, through a covalent link between $\beta$-1,6- and $\beta$-1,3-glucan and between $\beta$-1,3-glucan and chitin, GPI-anchored cell-wall proteins are connected also with these latter structurally important cell-wall polymers (Kollár et al. 1997; Levin 2011), strongly suggesting that GPI-anchored proteins play a central and direct role in cell-wall rigidity. Furthermore, GPI-anchored proteins are thought to play important roles in cell-wall organization because they exhibit cell surface-associated cell wall-synthesizing or -remodeling activities. A GPI-specific phospholipase $\mathrm{C}$ has been used to isolate GPI-anchored proteins and nine different GPI-anchored proteins of Aspergillus fumigatus with roles in cell-wall morphogenesis, including the $\beta$-1,3-glucanosyltransferases Gel1 and Gel4, the cell-wall glucanase Utr2, the acid phosphatase PhoA, the glycosidases Crh1p and Crh2p, and the cell-wall protein Ecm33, have been identified (Bruneau et al. 2001; Latgé 2007).

Pronounced reorganization of cell-wall composition is indispensable in some plant-pathogenic fungi in order to establish a compatible parasitic interaction with the host (El Gueddari et al. 2002; Fesel and Zuccaro 2016; Rovenich et al. 2016). For example, in Colletotrichum graminicola, the causal agent of maize leaf anthracnose and stem rot, dramatic downregulation of branched structural $\beta$-glucan contents is required at early stages of infection in order to avoid pathogen-associated molecular pattern (PAMP)-triggered immune responses (OliveiraGarcia and Deising 2013, 2016). Based on the structural role of GPI-anchored proteins in fungal cell walls one may speculate that these proteins may not only play a key role in vegetative hyphal growth (Bowman et al. 2006; Piłsyk and Paszewski 2009) but, also, contribute to functional reprogramming of the cell wall during the infection process. Intriguingly, mutagenesis of auxiliary genes involved in GPI-anchor synthesis in the opportunistic mammalian pathogens Aspergillus fumigatus and Candida albicans and in the plant pathogen Fusarium graminearum reduced fungal virulence and supports this idea (Li et al. 2007; Richard et al. 2002; Rittenour and Harris 2013).

In contrast to yeasts and filamentous fungi infecting mammalian hosts, some plant-pathogenic fungi undergo substantial infection-related morphogenesis (Mendgen and Deising 1993). C. graminicola and the rice blast fungus Magnaporthe oryzae differentiate elaborate melanized, pressurized infection cells, called appressoria, on the cuticle, in order to invade the epidermal host cell (Bastmeyer et al. 2002; Wilson and Talbot 2009). Appressoria of $C$. graminicola exert a force of approximately $17 \mu \mathrm{N}$, generated from turgor pressure corresponding to more than 50 bar (Bechinger et al. 1999), which highlights the requirement for rigid walls in these cells. Indeed, the importance of cell-wall rigidity is indicated by spontaneously exploding infection cells of $C$. graminicola RNA interference (RNAi) strains with reduced transcript abundance of the $\beta$-1,3-glucan synthase gene GLS1 and of the $\beta$-1,6-glucan synthesis genes KRE5 and KRE6, exhibiting reduced branched $\beta$-glucan contents (Oliveira-Garcia and Deising 2013, 2016). 
After breaching the plant cell wall, this hemibiotroph sequentially forms biotrophic primary and necrotrophic secondary hyphae (O'Connell et al. 2012). Clearly, the fact that in planta differentiated infection hyphae of mutants affected in $\beta$-glucan or chitin synthesis are severely distorted (Oliveira-Garcia and Deising 2013, 2016; Werner et al. 2007) further underscores the requirement for cell-wall rigidity also in these normally pressurized hyphae.

RNA interference (RNAi) has recently been established in C. graminicola (Oliveira-Garcia and Deising 2013), allowing us to study the role of essential genes in distinct infection cells in detail. Here, we employed RNAi to characterize three genes essential in the GPI-anchor synthesis pathway of C. graminicola, i.e., GPI12, encoding a $N$-acetylglucosaminylphosphatidylinositol deacetylase, as well as genes encoding the catalytic subunits of the transglutaminase complex, GAAl and GPI8. Reduction of transcript abundance of these three genes caused severe cellwall defects in vegetative hyphae, in appressoria, and in in planta-differentiated infection hyphae and, thus, led to loss of pathogenicity. Furthermore, studies employing inhibitors interfering with structural cell-wall polysaccharide microfibril formation, i.e., Calcofluor white and Congo red, highlight the structural role of GPI-anchored proteins.

\section{RESULTS}

The essential core GPI-anchor biosynthesis genes GPI12, $G A A 1$, and $G P I 8$ are indispensable

for vegetative hyphal growth and asexual sporulation.

In order to investigate the importance of GPI-anchor biosynthesis in the maize pathogen $C$. graminicola, we decided to interfere with this complex pathway at two distinct, i.e., early and late, steps and applied RNAi to reduce the transcript concentrations of the $N$-acetylglucosaminylphosphatidylinositol deacetylase gene GPII2 (gene annotation number GLRG_00461) (O'Connell et al. 2012) as well as of the genes GAA1 (glycosylphosphatidylinositol anchor attachment 1, GLRG_05637) and GPI8 (GLRG_06189) encoding two catalytic subunits of the GPI transamidase complex. These three genes are singlecopy genes in $C$. graminicola, and the derived proteins share significant similarity with the corresponding proteins of several other filamentous Ascomycota species (Fig. 2, in red). The similarity is particularly evident between proteins of different Colletotrichum species. As expected, sequences of yeasts and of Basidiomycota species (Fig. 2, in blue and green, respectively) are rather distantly related to $C$. graminicola proteins. For example, the amino acid identity of $C$. graminicola Gpi12, Gaa1, and Gpi8 with the corresponding C. higginsianum proteins is $81.9 ; 91.5$, and $94.2 \%$. The identity with the Magnaporthe oryzae proteins is $62.2 ; 64.9$, and $80.6 \%$. For comparison, the identity with the $S$. cerevisiae proteins is only 31.9 ; 34.8 , and $61.9 \%$, respectively. Gpi12, Gaa1, and Gpi8 exhibit distinct protein domains (Fig. 2). Gpi12 consists of 348 amino acids, has a short (five amino acids) ER-luminal sequence, a 21-amino acid transmembrane helix, and a 284amino acid putative deacetylase LmbE-like domain consisting of a three-layered alpha-beta-alpha-sandwich typically found in $\mathrm{N}$-acetylglucosaminyl-phosphatidylinositol de- $\mathrm{N}$-acetylases. Gaal is a 604-amino acid protein with seven transmembrane domains and a 464 amino acids long sequence with similarity to zinc peptidases and M28 family-type metallo-peptide synthetases. Gpi8 is a 415-amino acid protein with a 24-amino acid $N$-terminal eukaryotic signal peptide and a 231 amino acids long peptide synthetase $\mathrm{C} 13$ domain. The domain structures of Gpi12, Gaa1, and Gpi8 proteins of other species is similar to those of C. graminicola, with the exception of Ustilago species, which, in addition to the zinc peptidases/M28 family-type metallo-peptide synthetases domain characteristic of Gaa1, have a dolicholphosphate mannosyltransferase domain (Alg3) (Supplementary Fig. S1).

Notably, the disruption of these genes was lethal in S. cerevisiae (Benghezal et al. 1996; Hamburger et al. 1995; Watanabe et al. 1999) and, accordingly, attempts to inactivate GPI12, GAA1, and GPI8 by targeted gene deletion in C. graminicola was unsuccessful (data not shown). Therefore, we employed an RNAi strategy recently established in C. graminicola (Oliveira-Garcia and Deising 2013). The sense and corresponding antisense sequences used in RNAi constructs were 493, 560, and 690 bp for GPI12, GAA1, and GPI8, respectively, and the constitutive trpC promoter of Aspergillus nidulans (Yelton et al. 1984) was used to drive transcription of the RNAi constructs (Fig. 3A) (Oliveira-Garcia and Deising 2013). The nourseothricin resistance gene Nat-1 of Streptomyces noursei (Malonek et al. 2004) present on the RNAi constructs was under the control of the A. nidulans GPD promoter (Silar 1995). We obtained five, seven, and six independent transformants harboring the GPI12-, GAA1-, or GPI8-RNAi construct, respectively. As indicated by genomic Southern blot analyses, transformants contained one or two copies of the RNAi construct (Fig. 3B). Importantly, transcript abundances in the RNAi strains analyzed were strongly reduced, ranging between about 50 and $90 \%$, as indicated by reverse transcription-quantitative polymerase chain reaction (RT-qPCR) analyses (Fig. 3C).

In order to analyze the roles of GPI12, GAA1, and GPI8 in vegetative development, growth rates of three independent RNAi strains were determined on oat meal agar (OMA) and hyphal morphology was investigated microscopically (Fig. 4). Interestingly, even the strains with the weakest reduction of transcript abundance (GPI12-, GAA1-, and GPI8-RNAi strains), with transcript levels corresponding to 50 to $60 \%$ of the wild-type (WT) strain remaining, showed growth rate reductions between 70 and $75 \%$ (Figs. 3C and 4A). The addition of osmolytes such as $0.15 \mathrm{M} \mathrm{KCl}, 1 \mathrm{M}$ sorbitol, or $0.5 \mathrm{M}$ sucrose did not fully restore the growth rates of the RNAi strains. The strains with more strongly reduced transcript abundances, i.e., RNAi strains 2 and 3, showed even more severely reduced growth rates, clearly indicating the importance of GPI12, $G A A 1$, and GPI8 for hyphal growth. Interestingly, in contrast to vegetative hyphae of the WT strain, which developed long filaments, all RNAi strains analyzed by differential interference contrast (DIC) microscopy formed hyper-pigmented dark swellings on osmotically nonstabilized medium (Fig. 4B), suggesting that the hyphal cell walls were not rigid enough to control the turgor pressure. Only a few very short filaments growing out of a swelling were observed (Fig. 4B, GPI8-3, arrowhead). Occasionally, large swellings (Fig. 4B, GAA1-3, wide arrows point at cell walls of swollen hypha) containing intrahyphal hyphae were seen, but these were also misshapen (Fig. 4B, GAA1-3, asterisk). Interestingly, hyper-pigmented swellings also occurred in RNAi strains affected in synthesis of $\beta$-glucan, i.e., in GLS1- and in KRE5- and KRE6-RNAi strains, but, of these, only the KRE5- and KRE6-RNAi strains contained intrahyphal hyphae (Oliveira-Garcia and Deising 2013, 2016). Hyper-pigmentation of the RNAi strains studied here may indicate that GPI-anchored proteins contribute to linking $\beta$-glucan strands and cell-wall rigidity. However, why strains with defects in $\beta$-glucan formation are hyper-pigmented is unknown. Formation of intrahyphal hyphae has previously also been observed in class $\mathrm{V}$ chitin synthase mutants of C. graminicola (Werner et al. 2007). The overlapping phenotypes of GPI mutants with mutants impaired in GLS1, KRE5, and KRE6 and with $\triangle c h s V$ deletion mutants strongly suggest that GPI-anchored proteins are indispensable for formation of a 
functional cell-wall scaffold consisting of GPI-anchored proteins, chitin, and branched $\beta$-glucan.

Cell-wall defects in fungal hyphae become more pronounced in the presence of inhibitory compounds such as Calcofluor white or Congo red (Ram and Klis 2006). Calcofluor white has a high affinity to chitin and interferes with microfibril formation (Elorza et al. 1983), whereas Congo red is thought to preferentially interfere with $\beta$-1,3-glucan assembly (Kopecká and Gabriel 1992). Therefore these compounds have been used to fortify the hyphal defects observed in GPI12-, GAA1-, and GPI8-RNAi strains and to evaluate the role of GPI-anchored proteins in cross-linking of cell-wall polymers. As only minor changes in the structure of WT hyphae were observed at a concentration of $100 \mu \mathrm{g} \mathrm{ml}^{-1}$ Calcofluor white or Congo red, this concentration was chosen for cell-wall challenge experiments (Fig. 5A). On osmotically stabilized substratum, the hyphal morphology of the RNAi strains did not differ strongly from that of the WT strain. In the presence of Calcofluor white, the GPI12-, GAA1-, and GPI8-RNAi strains exhibited strong cell-wall defects, the severity of which increased with the reduction of transcript abundances of the genes. Large swellings occurred in hyphae of Calcofluor white-treated strains with reductions in GPI12-, GAA1-, and GPI8-transcript concentration exceeding $60 \%$ (Figs. 3C and 5A, Calcofluor white, arrows). Intriguingly, hyphal deformations were less severe in the presence of the $\beta$-1,3-glucan assembly inhibitor Congo red (Fig. 5A, Congo red).

The cell-wall disturbances, as caused by Calcofluor white and Congo red, were reflected also by the growth rates of the GPI12-, GAA1-, and GPI8-RNAi strains. Also, in radial growth assays, Calcofluor white was clearly more inhibitory than Congo red (Figs. 3C and 5B).

Formation of asexual spores is a critical step in fungal propagation. As sporulation defects were significant in mutants
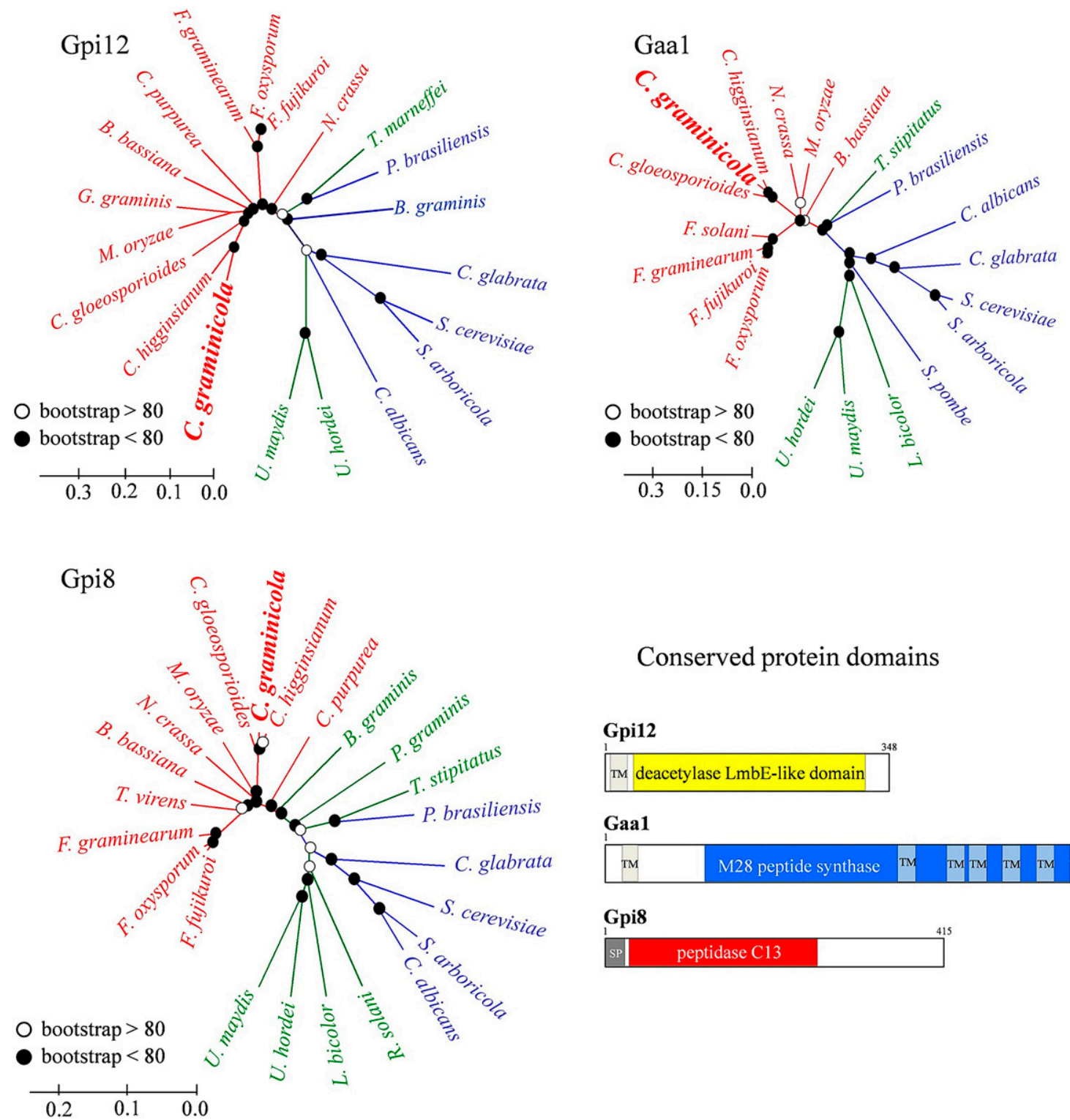

\section{Conserved protein domains}
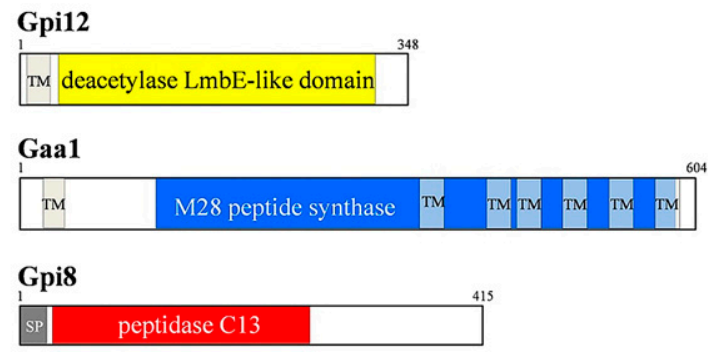

Fig. 2. Unrooted phylogenetic tree and protein domain structures of Gpi12, Gaa1, and Gpi8 of Colletotrichum graminicola. GPI12, GAA1, and GPI8 are singlecopy genes, encoding a putative $N$-acetylglucosaminylphosphatidylinositol deacetylase and the catalytic subunits of the transglutaminase complex, a putative metallo-peptide-synthetase and a putative cystein protease. The proteins of Ascomycota members are closely related and form a clade (red). Proteins of yeasts are given in blue, Basidiomycota proteins in green. A conserved putative protein domain search indicated single (Gpi12) or multiple (Gaa1) transmembrane helices (TM) and a eukaryotic secretion signal (Gpi8). The deacetylase domain of Gpi12, the M28 metallo-peptide synthase domain of Gaa1, and the peptidase $\mathrm{C} 13$ domain are given in yellow, blue, and red. 
affected in cell-wall biogenesis (Oliveira-Garcia and Deising 2013, 2016) and as GPI-anchored proteins play enzymatic roles in cell-wall formation and structural roles in cell-wall rigidity, we studied formation of conidia by GPI12-, GAA1-, and GPI8RNAi strains. Interestingly, like GLS1-, KRE5-, and KRE6RNAi strains, conidiation of GPI12-, GAA1-, and GPI8-RNAi strains on OMA required osmotic stabilization (Oliveira-Garcia and Deising 2013, 2016). On nonstabilized medium, only the WT strain conidiated (Fig. 6A, WT, black bars). On OMA complemented with $0.15 \mathrm{M} \mathrm{KCl}$ or $1 \mathrm{M}$ sorbitol, conidia were produced by GPI12-, GAA1-, and GPI8-RNAi strains, but the rate of conidiation was significantly lower than that of the WT strain (Fig. 6A, white and gray bars). Importantly, RNAi strains showing strongly reduced transcript abundance, i.e., GPI12RNAi strains 4 and 5, GAAl-RNAi strains 5, 6, and 7, and GPI8-RNAi strains 4, 5, and 6 failed to sporulate completely (Figs. 6A and 3C). Quantification of transcript abundance and rates of conidiation suggests that reduction of transcript abundance by about $90 \%$ in the case of GPII2 and by about $70 \%$ in the case of the GPI transamidase complex genes GAAl and GPI8 is required for complete elimination of asexual sporulation on osmotically stabilized media.

Not only the number but, also, the size and shape of spores were affected in GPI-anchor mutants. On OMA supplemented with $1 \mathrm{M}$ sorbitol, the WT strain formed falcate conidia (Fig. $6 \mathrm{~B}, \mathrm{WT}$ ). In comparison, the GPI12-, GAA1-, and GPI8-RNAi strains formed shorter spores with increased diameters, leading to an oval to bean-like swollen phenotype (Fig. 6B and C, GPI12-2, GAA1-2 and GPI8-2 compared with WT). The phenotype of conidia of GPI12-, GAA1-, and GPI8-RNAi strains may be well-explained by reduced cell-wall rigidity.

\section{GPI12, GAA1, and GPI8 are required for differentiation} of functional appressoria and for pathogenicity.

In the majority of plant-pathogenic fungi, host infection is initiated by differentiation of appressoria that, after maturation and generation of enormous turgor pressure, breach the host epidermal cell wall (Bastmeyer et al. 2002; Wilson and Talbot 2009). Defects in structural components of the appressorial cell-wall network, e.g., of chitin and branched $\beta$-glucan, caused nonpathogenicity in C. graminicola (Oliveira-Garcia and Deising 2013, 2016; Werner et al. 2007). GPI anchors are thought to play a role in cross-connecting cell-wall $\beta$-glucan polymers and, thus, presumably also in cell-wall rigidity (Piłsyk and Paszewski 2009). Therefore, we investigated rates of appressorium differentiation and appressorial integrity in two independent GPI12-, GAA1-, and GPI8-RNAi strains, each (Fig. 7). In the RNAi strains analyzed, reduced transcript abundances correlated with reduced germination and appressorium formation rates (Figs. 3C and 7A). Appressoria of these strains, like those formed by the WT, were strongly melanized (Fig. 7B, arrowheads) but, unlike WT appressoria, intriguingly, infection cells of all RNAi strains formed on polyester surfaces, exploded spontaneously at high frequencies (Fig. 7B, arrows, and $\mathrm{C}$ ). Spontaneous appressorial cell-wall rupturing has also been reported for GLS1-, KRE5-, and KRE6-RNAi strains (Oliveira-Garcia and Deising 2013, 2016). Again, these observations highlight the importance of GPI-anchor formation

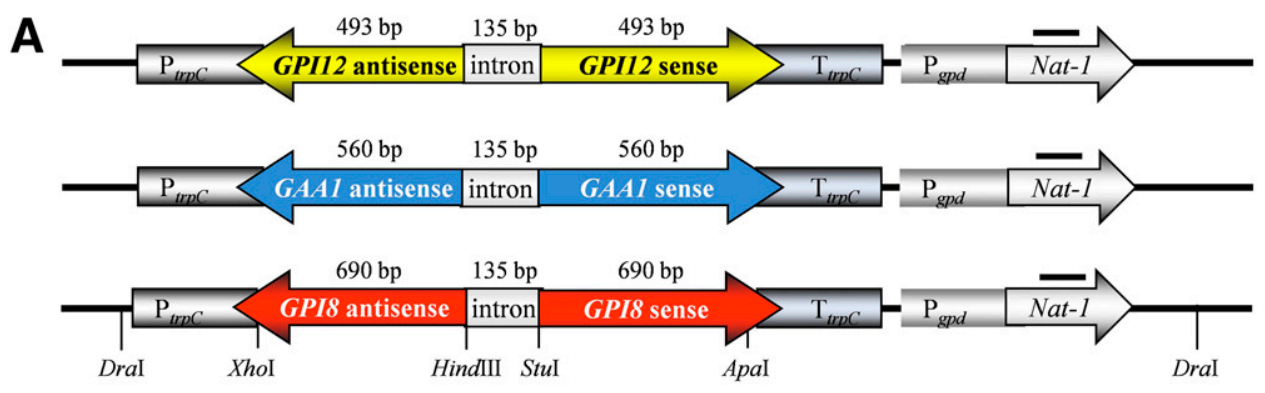

B
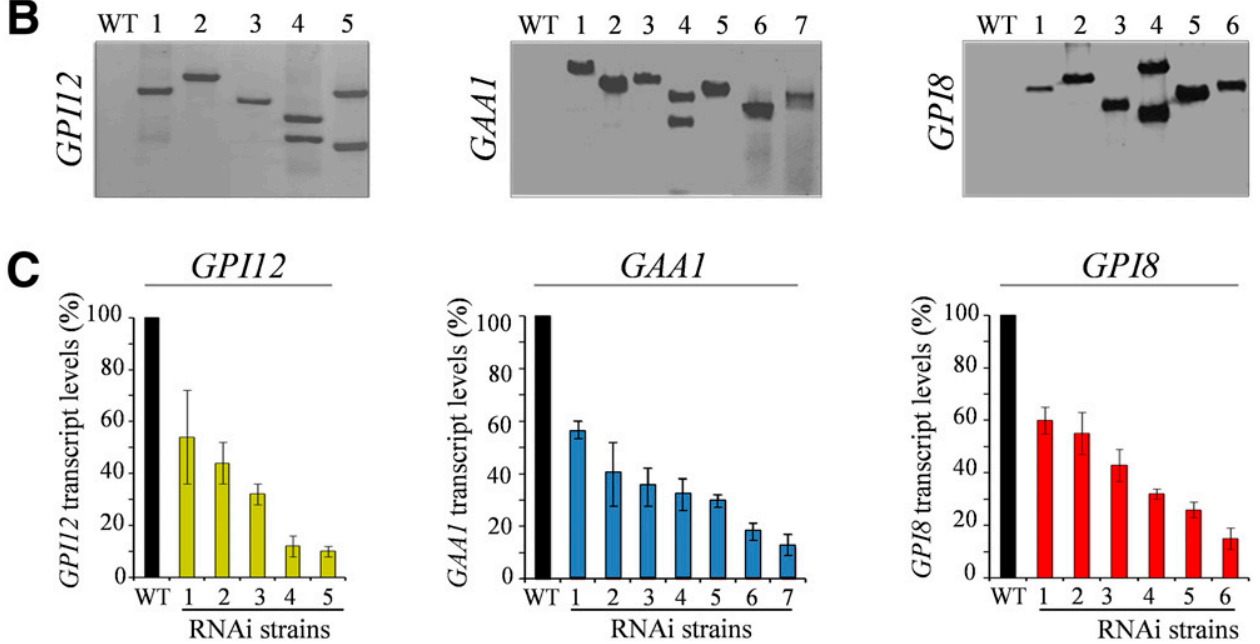

Fig. 3. RNA interference (RNAi) constructs generated and reduction of transcript abundance of GPI12, GAA1, and GPI8 in Colletotrichum graminicola RNAi strains. A, Structure of RNAi constructs. Transcription of RNAi constructs is controlled by the trpC promoter and terminator of Aspergillus nidulans, transcription of the nourseothricin-resistance cassette is driven by the A. nidulans gpd promoter. The second intron of the Magnaporthe oryzae cutinase gene CUT2 links the sense and antisense fragments. The bar over the Nat-1 gene shows the position of the digoxygenin-labeled probe used to visualize the constructs in genomic Southern blots. B, Genomic Southern blots showing the number of integrated RNAi cassettes. Genomic DNA had been digested by XhoI. C, GPI12, $G A A 1$, and GPI8 transcript abundance in the C. graminicola wild type (WT) and in the RNAi strains measured by reverse transcription-quantitative polymerase chain reaction. 
for appressorial cell-wall rigidity and for function of these infection cells.

Appressorial cell-wall defects lead to reduced penetration competence (Oliveira-Garcia and Deising 2013, 2016). In order to analyze pathogenicity or virulence defects resulting from loss of appressorial penetration competence, we inoculated conidia of GPI12-, GAA1-, and GPI8-RNAi strains onto intact maize leaf surfaces. In full agreement with the appressorial defects observed on artificial substrate (Fig. 7B), we also observed ruptured appressoria of GPI12-, GAA1-, and GPI8RNAi strains on intact leaf surfaces (data not shown). As appressoria of these strains exploded on artificial surfaces, we expected that the GPI12-, GAA1-, and GPI8-RNAi strains would have reduced capabilities of invading the host tissue. Indeed, even RNAi strains with transcript abundances only moderately reduced by 40 to $50 \%$ were unable to invade the plant and to cause anthracnose disease symptoms. Intact maize leaves inoculated with the WT strain showed severe anthracnose disease symptoms 5 days after inoculation (Fig. 8A, nonwounded). When inoculated into wounds, $C$. graminicola does not differentiate appressoria and invades the leaf with necrotrophic hyphae, omitting the biotrophic stage of infection (Oliveira-Garcia and Deising 2013). Thus, infection assays on wounded leaves were performed to circumvent the appressorial penetration defects and to allow the fungus to differentiate necrotrophic secondary hyphae directly (Oliveira-Garcia and Deising 2013). On wounded leaves, minor necrotic lesions were observed at the margins of the wounds but, as compared with the disease symptoms caused by the WT strain, the symptoms caused by the mutants were negligible (Fig. 8A, wounded). Quantification of fungal DNA by qPCR analyses fully confirmed poor pathogenic development of the C. graminicola mutants on wounded leaves (Fig. 8B). Furthermore, DIC microscopy showed that the WT strain inoculated onto wounded leaves extensively colonized its host and formed thin, fast-growing secondary hyphae indicative of a necrotrophic lifestyle (Fig. 8C, WT, arrowhead) and these hyphae frequently breached plant cell walls (Fig. 8C, WT, arrow). In contrast, all RNAi strains tested showed severely distorted infection hyphae, exhibiting large swellings (Fig. 8C, RNAi
A

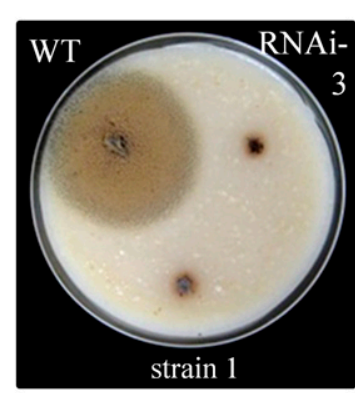

GPII2-RNAi
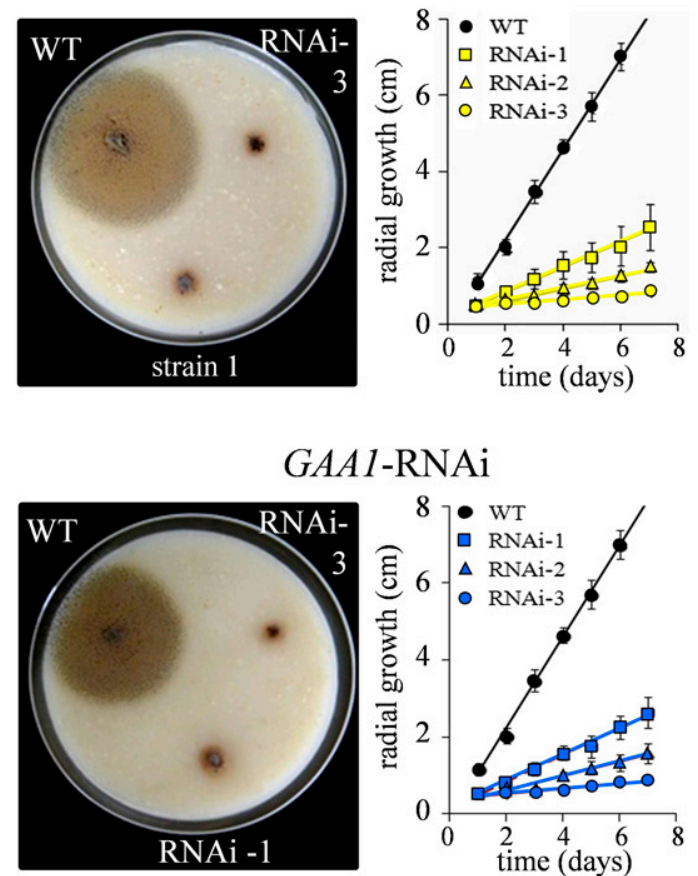

GAAI-RNAi

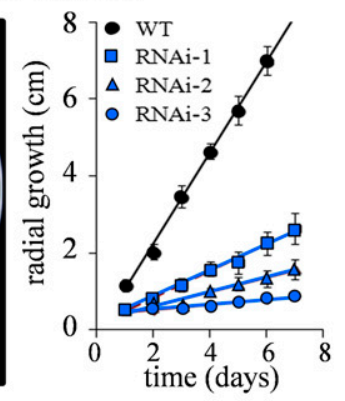

\section{GPI8-RNAi}
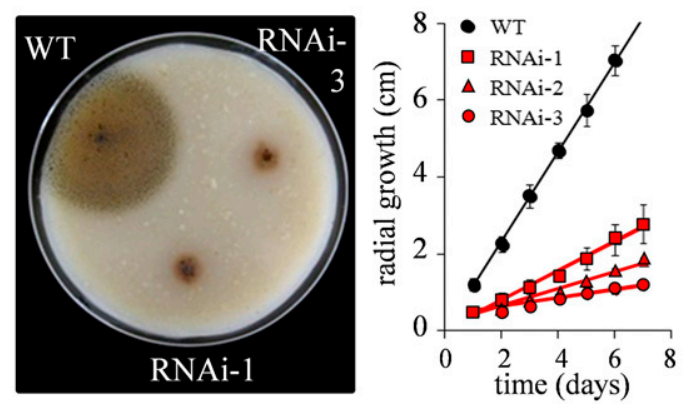

B
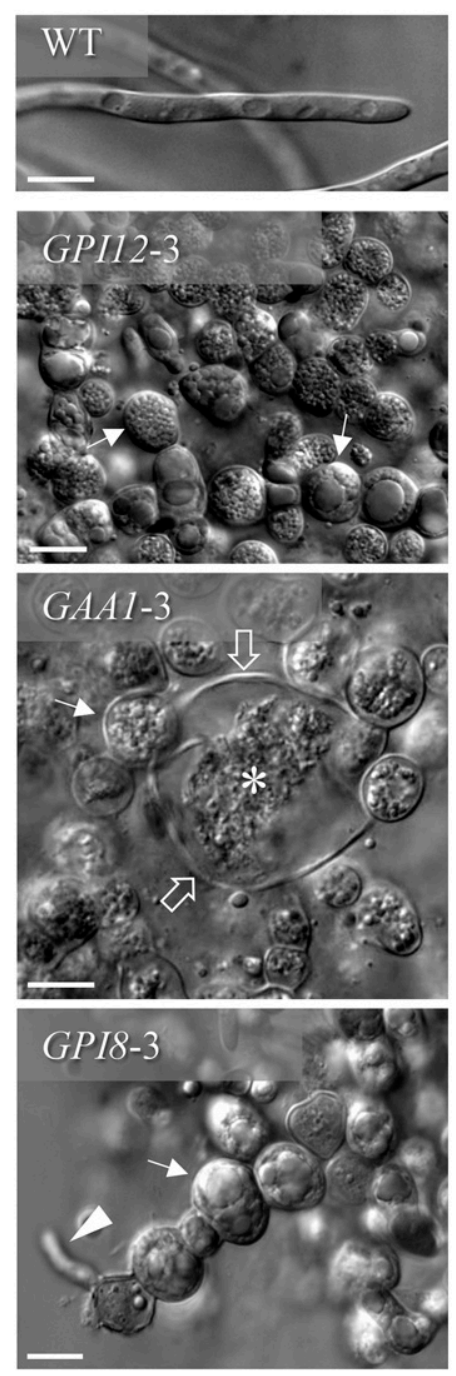

Fig. 4. Vegetative development of the Colletotrichum graminicola wild type (WT) and RNA interference (RNAi) strains. A, Morphology of colonies (left panel) and growth rates (right panel) of WT and three selected GPI12-, GAA1-, and GPI8-RNAi strains on oat meal agar supplemented with 0.15 M KCl. Error bars represent \pm standard deviations. B, Vegetative hyphae of the WT strain and strains GPI12-3, GAA1-3, and GPI8-3. The RNAi strains show hyphal swellings (arrows). Some swollen hyphae (GAAl-3, wide arrows) contain intrahyphal hyphae (asterisk). The arrowhead points at an outgrowing filament. Osmotically nonstabilized medium has been used in these experiments. Bars are $10 \mu \mathrm{m}$. 
strains, asterisks) connected by short stretches of nonswollen hyphae (Fig. 8C, RNAi strains, arrowhead). Randomly occurring swellings suggest that the cell-wall rigidity of all RNAi strains is insufficient to control hyphal turgor pressure and to maintain the shape of pathogenic hyphae.

Taken together, the data shown here indicate that GPI-anchor synthesis is required for vegetative hyphal growth, conidiation, differentiation of functional appressoria, and pathogenic inplanta development of the maize pathogen $C$. graminicola.

\section{DISCUSSION}

Synthesis of GPI anchors is mediated by a series of complex ER-associated enzymatic reactions. The transfer of the anchor to proteins by the GPI transamidase complex is required for directing secreted proteins to, and associating them with, the plasma membrane. In fungi, some of these proteins are remobilized by truncation of the GPI anchor, are covalently crosslinked to structural cell-wall carbohydrate polymers, and contribute to cell-wall strengthening (Castillo et al. 2003; Ecker et al. 2006; Levin 2011). Other GPI-anchored proteins, however, remain associated with the plasma membrane and have enzymatic functions, e.g., in cell-wall remodeling or virulence, or both (Abad et al. 2010; Bowman et al. 2006; de MedinaRedondo et al. 2010; Latgé 2007; Siafakas et al. 2006).

The number of predicted GPI-anchored proteins may differ considerably in fungal species, depending on their taxa and lifestyle. Genome-wide analysis of preselected secreted proteins (Krijger et al. 2014) by the fungal big- $\Pi$ prediction program, designed to discover potential GPI modification sites in fungal proteins (Eisenhaber et al. 2004), indicated that the genomes of the plant-pathogenic Ascomycota $F$. graminearum and $M$. oryzae harbor 84 and 80 genes encoding predicted GPI-anchored proteins. The genome of the closely related filamentous human pathogenic ascomycete A. fumigatus harbors only 46 of such genes, and the human pathogenic yeasts Candida glabrata and Candida albicans harbor 39 and 58. Interestingly, the dimorphic basidiomycete Ustilago maydis, which exhibits a biotrophic lifestyle, is predicted to contain only 16 GPI-anchored proteins (Jorrit-Jan Krijger, MLU Halle, personal communication). Unfortunately, as only few GPIanchor synthesis genes and genes encoding GPI-anchored proteins have, as yet, been functionally analyzed in a limited number of pathogenic fungi, the importance of GPI-anchor biosynthesis in pathogenic development can be considered poorly understood.

The comprehensive list of GPI-anchored proteins of the opportunistic human pathogen Candida albicans (Richard and Plaine 2007) not only displays the complexity and functional diversity of these proteins but, also, highlights the importance of GPI-anchor biosynthesis. In accordance with the presumed role of GPI-anchored proteins in cell-wall rigidity, $\Delta$ gpi7 mutants of Candida albicans were more sensitive to Calcofluor white than the WT strain and a revertant (Richard et al. 2002). Interestingly, mouse models of hematogenously disseminated candidiasis and gastrointestinal tract colonization clearly demonstrated a role of GPI7 in fungal virulence. In contrast to WT cells, $\triangle$ gpi7 cells were unable to interfere with phosphorylation-mediated activation of the signal-regulated kinases Erk1 and Erk2, which have a major function in defense responses to pathogens, after phagocytosis by macrophages (Richard et al. 2002). The authors hypothesize that the mutant cells do not possess or present proteins involved in the modulation of these kinases. However, as these mutants may, alternatively, have cell-wall integrity defects, as suggested by formation of a hyperbranched pseudomycelium and abnormal cells, activation of defense and resulting loss of virulence may also be due to exposition of PAMPs that may be masked by GPI-anchored proteins or their products in the WT strain. Likewise, $\Delta$ gpi 7 mutants of Fusarium graminearum, the causal agent of stalk, ear, and kernel rot of maize and of head blight of wheat, showed virulence defects, as indicated by reduced rates of ramification of this fungus throughout the rachis of wheat heads. The mutants had cell-wall defects, as shown by transmission electron microscopy, and were more sensitive to protoplasting enzymes and Calcofluor white than the corresponding WT strain (Rittenour and Harris 2013). In A. fumigatus causing fatal invasive aspergillosis in immunocompromised patients, a $\Delta$ gpi3 mutant has been generated and employed in virulence analyses. Gpi3 is thought to be the catalytic subunit of the $\mathrm{N}$-acetyl glucosaminyl transferase complex. Histological analyses of lung tissue from mice inoculated with WT conidia showed more prominent necroses than corresponding lung tissues infected by the $\Delta g p i 3$ mutant, suggesting attenuated virulence of the mutant ( $\mathrm{Li}$ et al. 2007). As shown for the $\Delta$ gpi7 mutants of Candida albicans and $F$. graminearum, $\Delta$ gpi3 mutants of A. fumigatus exhibit severe cell-wall defects, as indicated by

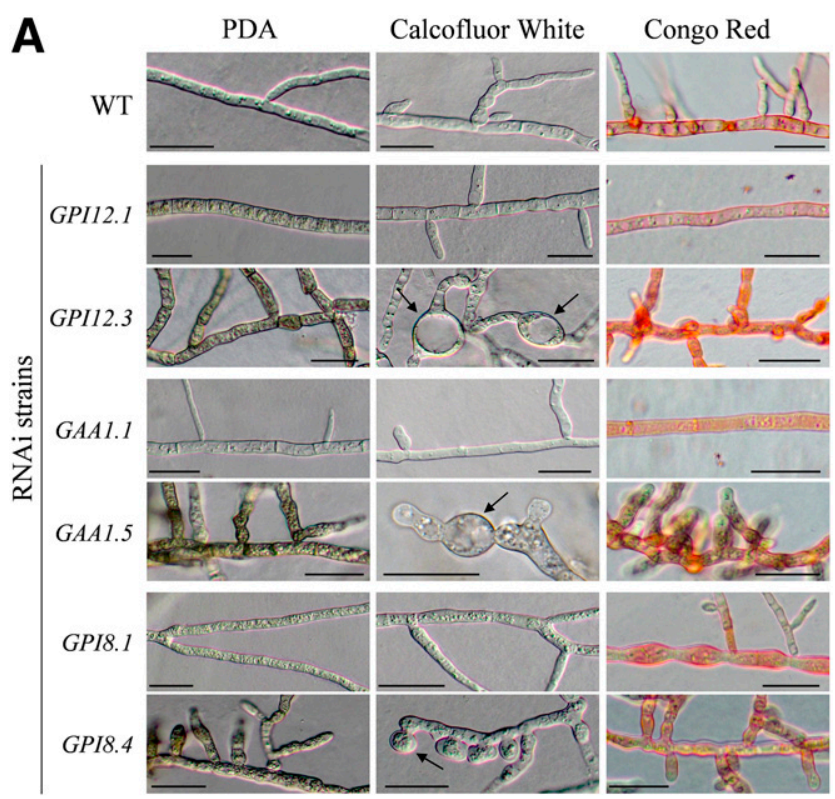

B

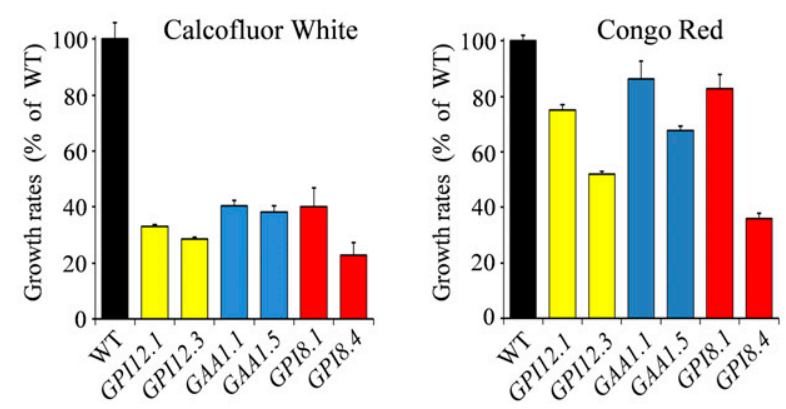

Fig. 5. Effect of the cell wall-disturbing agents Calcofluor white and Congo red on the integrity of vegetative hyphae of Colletotrichum graminicola grown on potato-dextrose agar supplemented with $0.15 \mathrm{M} \mathrm{KCl}$. A, Calcofluor white causes severe hyphal swellings in RNA interference (RNAi) strains. The degree of perturbation correlates with the transcript abundances of GPI12, GAA1, and GPI8. In comparison with Calcofluor white, the effects of Congo red are moderate. Scale bars are $25 \mu \mathrm{m}$. B, Relative growth rates of RNAi strains are severely reduced on agar containing Calcofluor white and moderately in the presence of Congo red. Cultures were grown for 5 days, and growth rates relative to that of the wild type (WT) strain are given. Error bars represent + standard deviations. 
increased sensitivity to Calcofluor white or Congo red, allowing the hypothesis that reduced cell-wall rigidity may be the reason for reduced virulence in the GPI biosynthesis mutants discussed.

So far, indispensable genes of the GPI biosynthesis pathway have not been analyzed in pathogenic fungi. Here, taking advantage of RNAi (Oliveira-Garcia and Deising 2013), we investigated the role of the $\mathrm{N}$-acetylglucosaminyl-phosphatidylinositol deacetylase gene GPII2 and of two genes encoding catalytic subunits of the GPI transamidase complex, i.e., GAAland GPI8, in C. graminicola. Intriguingly, these RNAi strains formed vegetative intrahyphal hyphae as previously observed in $C$. graminicola chitin synthase, i.e., $\Delta c h s V$ deletion strains (Werner et al. 2007) and in corresponding chitin synthase mutants of $A$. nidulans and $F$. graminearum (Horiuchi et al. 1999; Kim et al. 2009). Using repeat-induced point mutation (RIP), Bowman and coworkers (2006) generated mutants of Neurospora crassa defective in homologs of yeast MCD4 and $G P I 13$, encoding the first and third ethanolamine phosphotransferase, as well as of the homolog of S. cerevisiae GPI16. GPII6 encodes a subunit of the GPI transamidase complex without known catalytic activity but is thought to be required for formation and stabilization of the complex. Importantly, the $N$. crassa RIP strains carrying mutations in the GPII3 and GPII6 homologs showed an abnormal "cell within a cell" phenotype, reminiscent of the intrahyphal hyphae observed in the C. graminicola GPI12-, GAA1-, and GPI8-RNAi strains and also of $\triangle$ gpi3 strains of A. fumigatus (Li et al. 2007). Remarkably, the phenotypic overlap of GPI-RNAi strains with chitin synthase mutants is surprising because GPIanchor proteins are thought to be directly linked to $\beta$-glucans and only indirectly to chitin chains through a covalent $\beta-1,4$-bond between the terminal reducing residue of a chitin chain and the nonreducing end of a $\beta$-1,3-glucan chain (Kollár et al. 1995, 1997).

In contrast to Candida albicans, $F$. graminearum, and A. fumigatus, which do not differentiate distinct infection structures, C. graminicola successively differentiates pressurized appressoria on the plant cuticle and biotrophic and necrotrophic hyphae in the host tissue (Bergstrom and Nicholson 1999), allowing evaluation of the importance of GPI-anchor biosynthesis in individual infection cells. Intriguingly, appressoria of all RNAi strains exploded spontaneously, and even normally pressurized in planta-differentiated infection hyphae developed swellings, indicative of severe cell-wall defects. These pathogenic hyphae also showed phenotypic overlaps with mutants defective in $\beta$-glucan synthesis, i.e., swellings and hyperpigmentation, as well as with those defective in chitin synthesis, i.e., formation of intrahyphal hyphae (Oliveira-Garcia and Deising 2013, 2016; Werner et al. 2007). The fact that appressoria ruptured and the resulting inability to invade the host are fully sufficient to explain nonpathogenicity on intact maize leaves, and the severity of the cell-wall defects of necrotrophic hyphae strongly suggested that lack of cell-wall rigidity was causative for the dramatic virulence defect after wound inoculation.

As indicated above, cell-wall function and fungal virulence are intimately interconnected. It may, therefore, not be surprising that GPI-anchored $\beta$-1,3-glucanosyltransferases are required for fungal virulence on taxonomically distinct hosts. Deletion of the GEL2 gene of A. fumigatus caused alterations in cell-wall composition and reduced virulence in a murine model of invasive aspergillosis (Mouyna et al. 2005). Moreover, $\Delta$ gas 1 mutants of the entomopathogenic fungus Beauveria bassiana showed reduced virulence in the greater wax moth Galleria mellonella (Zhang et al. 2011) and the deletion of GPIanchored $\beta$-1,3-glucanosyltransferase GAS1 caused reduced virulence of the vascular wilt fungus of tomato, i.e., Fusarium oxysporum, as demonstrated in root infection and fruit tissue invasion assays (Caracuel et al. 2005). In major contrast to the pathogens discussed above, powdery mildew fungi exhibit an

A

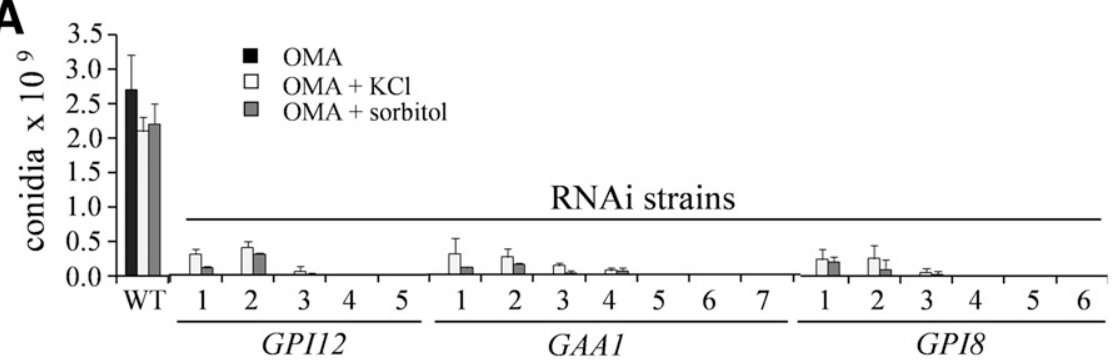

B
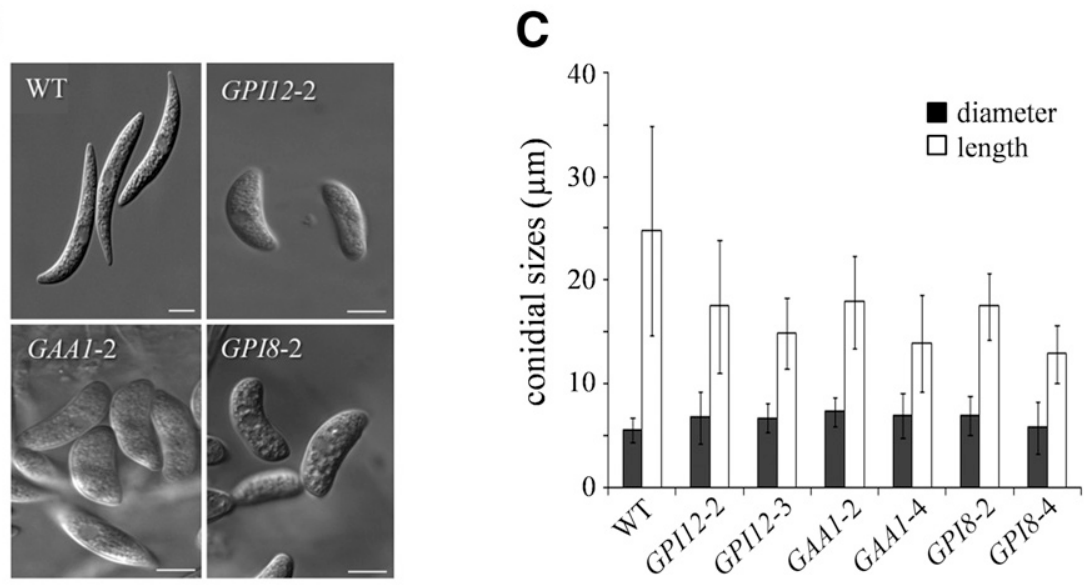

Fig. 6. RNA interference (RNAi)-mediated reduction of GPI12, GAA1 and GPI8 transcript abundances causes reduction of sporulation rates and abnormal spore shapes. (A) Asexual sporulation rates of the wild type (WT) strain and of independent RNAi strains on oat meal agar (OMA) in the presence or absence of different osmolytes $(0.15 \mathrm{M} \mathrm{KCl}$ or $1 \mathrm{M}$ sorbitol). In all RNAi strains, irrespective of the osmolyte added, sporulation rates were strongly reduced. B, Shape of the conidia of WT and of RNAi strains GPI12-2, GAA1-2, and GPI8-2. Conidia had formed on OMA containing $0.15 \mathrm{M}$ KCl. Size bars are $10 \mu \mathrm{m}$. C, Conidial sizes of WT and different RNAi strains. Conidia had formed on OMA containing $0.15 \mathrm{M} \mathrm{KCl}$. Error bars represent \pm standard deviations. 
obligate biotrophic lifestyle, i.e., they are only able to grow on cells of living hosts. Due to their biotrophic lifestyle, transformation protocols do not exist and targeted gene deletion experiments cannot be performed. However, Nowara et al. (2010) established a method referred to as host-induced gene silencing (HIGS) and showed that the accumulation of either double-stranded or antisense RNA in barley and wheat, targeting the transcripts of the two fungal GPI-anchored $\beta-1,3$ glucanosyltransferase genes $G T F 1$ and $G T F 2$, reduced transcript abundances of these genes in the pathogen and significantly reduced rates of host invasion, haustorium formation, and virulence of the powdery mildew fungus Blumeria graminis.

The data presented in this work do not only deepen our understanding of GPI-anchor synthesis in fungal pathogenesis but, also, help in identifying novel targets for HIGS. As mentioned above, HIGS of GTF1 and GTF2 improved resistance against powdery mildew in barley and wheat (Nowara et al. 2010) and HIGS of CYP51 genes, encoding the azole fungicide target cytochrome P450 lanosterol C14 $\alpha$-demethylase, conferred strong resistance to Fusarium species infecting cereals or the model plant Arabidopsis (Koch et al. 2013). Consistent with the proposal of applying HIGS to interfere with GPI-anchor synthesis is the note that, in a conditional GPI3 expression mutant of A. fumigatus, GPI concentration was moderately reduced to $78 \%$, yet caused significant rates of fungal cell death, possibly through induction of autophagy and necroptosis (Yan et al. 2013). The data presented by Yan and coworkers are of particular interest, as they suggest that even a minor reduction of GPI synthesis through HIGS might not only affect hyphal integrity and growth rate but might efficiently inactivate the invading pathogen at early stages of infection.

In summary, taking advantage of RNAi-mediated reduction of GPII2, GAA1, and GPI8 transcript abundances, we provide direct evidence for the virulence function of these essential GPI pathway genes in a plant-pathogenic fungus and suggest them as novel HIGS targets to be used in molecular breeding of pathogen-resistant plants.

\section{MATERIALS AND METHODS}

Fungal strains, culture conditions, appressorium differentiation, and virulence assays.

The WT strain M2 of Colletotrichum graminicola (Ces.) G.W. Wilson and RNAi strains generated in this study were cultivated on OMA (Werner et al. 2007), potato-dextrose agar (PDA) (Difco Laboratories, Sparks, MD, U.S.A.), or on PDA supplemented with either $100 \mu \mathrm{g}$ Calcofluor white or Congo red per milliliter of PDA. As RNAi strains required osmotic stabilization, the media were supplemented with $0.15 \mathrm{M} \mathrm{KCl}$ or $1 \mathrm{M}$ sorbitol. Complete medium (Leach et al. 1982) was used as a liquid growth medium. Liquid cultures were grown in a rotary incubation shaker (Unitron, Infors, Bottmingen, Switzerland) at $110 \mathrm{rpm}$ and $23^{\circ} \mathrm{C}$. Solidified media contained $1.5 \%$ (wt/vol) agar-agar (Difco Laboratories), and cultures were grown at $23^{\circ} \mathrm{C}$ under continuous fluorescent light (Climas Control CIR, UniEquip, Martinsried, Germany) (Werner et al. 2007).

Appressoria of the WT and RNAi strains were allowed to differentiate on polyester or glass microscopy cover slips as described (Horbach et al. 2009; Oliveira-Garcia and Deising 2013).

Virulence assays were performed by inoculating $10 \mu \mathrm{l}$ droplets containing $10^{4}$ conidia in $0.01 \%$ ( $\mathrm{vol} / \mathrm{vol}$ ) Tween 20 onto nonwounded and wounded leaf segments of 12-day-old maize (Zea mays cv. Mikado) plants as described (Horbach et al. 2009; Oliveira-Garcia and Deising 2013). Mock inoculation was performed with $0.01 \%$ (vol/vol) Tween 20 . Plants were incubated in a Percival AR-75L growth chamber (Percival, Perry, IA, U.S.A.) (12 h of light; $200 \mu \mathrm{E} ; 70 \%$
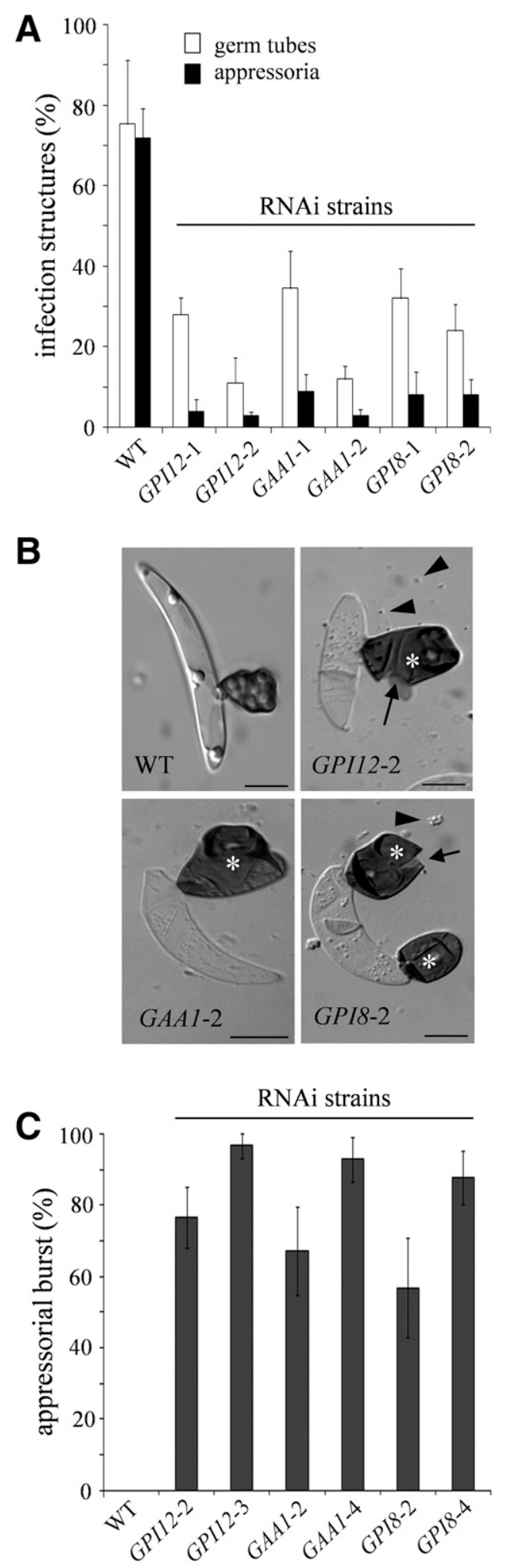

Fig. 7. Reduction of transcript abundances of GPI12, GAA1, and GPI8 affects germination and appressorium differentiation rates and appressorial cell-wall rigidity. A, Quantification of germination and appressorium differentiation on polyester. In each of the three independent experiments performed, 200 infection structures have been counted. Error bars represent + standard deviations. B, On polyester surfaces, conidia of the WT strain formed short germ tubes and melanized appressoria (WT). Conidia of GPI12-, GAA1-, and GPI8-RNA interference (RNAi) strains germinated and formed appressoria, many of which burst (arrow), released lipid droplets (arrowheads), and collapsed (asterisks). Size bars are $10 \mu \mathrm{m}$. C, Quantification of rates of rupturing of appressoria. While appressoria of the WT strains did not burst on polyester surfaces, the vast majority of the appressoria of all RNAi strains exploded. Error bars represent +standard deviations. 
relative humidity; $25^{\circ} \mathrm{C}$ ). Disease symptoms were photographed 5 days after inoculation.

All experiments were performed in triplicate and with four technical repetitions.

\section{Construction of GPI12-, GAA1-, and GPI8-RNAi strains of $C$. graminicola.}

For RNAi-mediated reduction of GPI12, GAA1, and GPI8 transcript concentrations, the RNAi cassette from plasmid pREDi (Janus et al. 2007) was used to generate GPI12-, GAA1-, and GPI8-RNAi constructs. The 493-bp GPI12, 560-bp GAA1, and 690-bp GPII2 sense and antisense fragments were amplified from genomic DNA of C. graminicola, using the following primer combinations (these and all other PCR primers used in this work are given in Supplementary Table S1): RNAi(GPI-12) SmaI-Fw and RNAi(GPI-12)SmaI-Rv for GPI12; RNAi(GAA1) XhoI-Fw and RNAi(GAA1)HindIII-Rv and RNAi(GAA1)StuIFw and RNAi(GAA1)ApaI-Rv for GAAl; and RNAi(GPI-8) XhoI-Fw and RNAi(GPI-8)HindIII-Rv and RNAi(GPI-8)BglIIFw and RNAi(GPI-8)ApaI-Rv for GPI8. The XhoI-HindIII and StuI-ApaI fragments of pREDi were replaced by the GPI8, $G A A 1$, and GPI12 sense and antisense fragments. The resulting RNAi constructs were excised from pREDi by DraI digestion, were purified by gel elution, and were transformed into conidial protoplasts of $C$. graminicola (Oliveira-Garcia and Deising 2013). The nourseothricin acetyltransferase gene (Malonek et al. 2004) was employed to select transformants. Single-spore isolates were generated as described (Werner et al. 2007).

DNA extraction and genomic DNA gel blot analysis.

Extraction of genomic DNA and Southern blot analyses were performed as described (Werner et al. 2007). Ten milligrams of
XhoI-digested total DNA was used to analyze transformants for the number of RNAi constructs integrated into the genomes. The 511-bp nourseothricin acetyl transferase gene (Nat-1)-specific alkali-labile digoxigenin-dUTP-labeled (Roche Diagnostics, Mannheim, Germany) probe was amplified from plasmid pNRl (Malonek et al. 2004), using primers NatR probe-Fw and NatR probe-Rv.

\section{qPCR and RT-qPCR.}

Fungal pathogenic development in Z. mays leaves was quantified by qPCR as described (Horbach et al. 2009; Oliveira-Garcia and Deising 2013), using $100 \mathrm{nM}$, each, of primers CgITS2-q1 and CgITS2-q2 (Behr et al. 2010). All values are standardized to the average threshold cycle $(\mathrm{Ct})$ value obtained with DNA extracted from leaves inoculated with the $C$. graminicola WT strain at $0 \mathrm{~h}$ after inoculation.

Transcript abundance was quantified by RT-qPCR as described, using $100 \mathrm{ng}$ of RQ1 RNase-free DNase-pretreated (Promega, Madison, WI, U.S.A.) total RNA as described (Horbach et al. 2009; Oliveira-Garcia and Deising 2013). RTqPCR primers CgGPI12RTqPCR-Fw and CgGPI12RTqPCRRv, CgGAA1RTqPCR-Fw and CgGAA1RTqPCR-Rv, and CgGPI8RTqPCR-Fw and CgGPI8RTqPCR-Rv were used to quantify GPII2, GAA1, and GPI8 transcripts. Melting curve and agarose gel analyses confirmed amplification of single products. Transcript abundance was calculated and normalized as described (Horbach et al. 2009), using $\alpha$-actin and histone $\mathrm{H} 3$ genes of $C$. graminicola as reference. Primers for transcripts of $\alpha$-actin and histone $\mathrm{H} 3$ genes were $\mathrm{CgACTqRT}-\mathrm{F} 1$ and CgACTqRT-R1 and CgH3-qRT.F1 and CgH3-qRT.R1 (Krijger et al. 2008). Ct values of three independent replicates were used to calculate mean values and standard deviations.
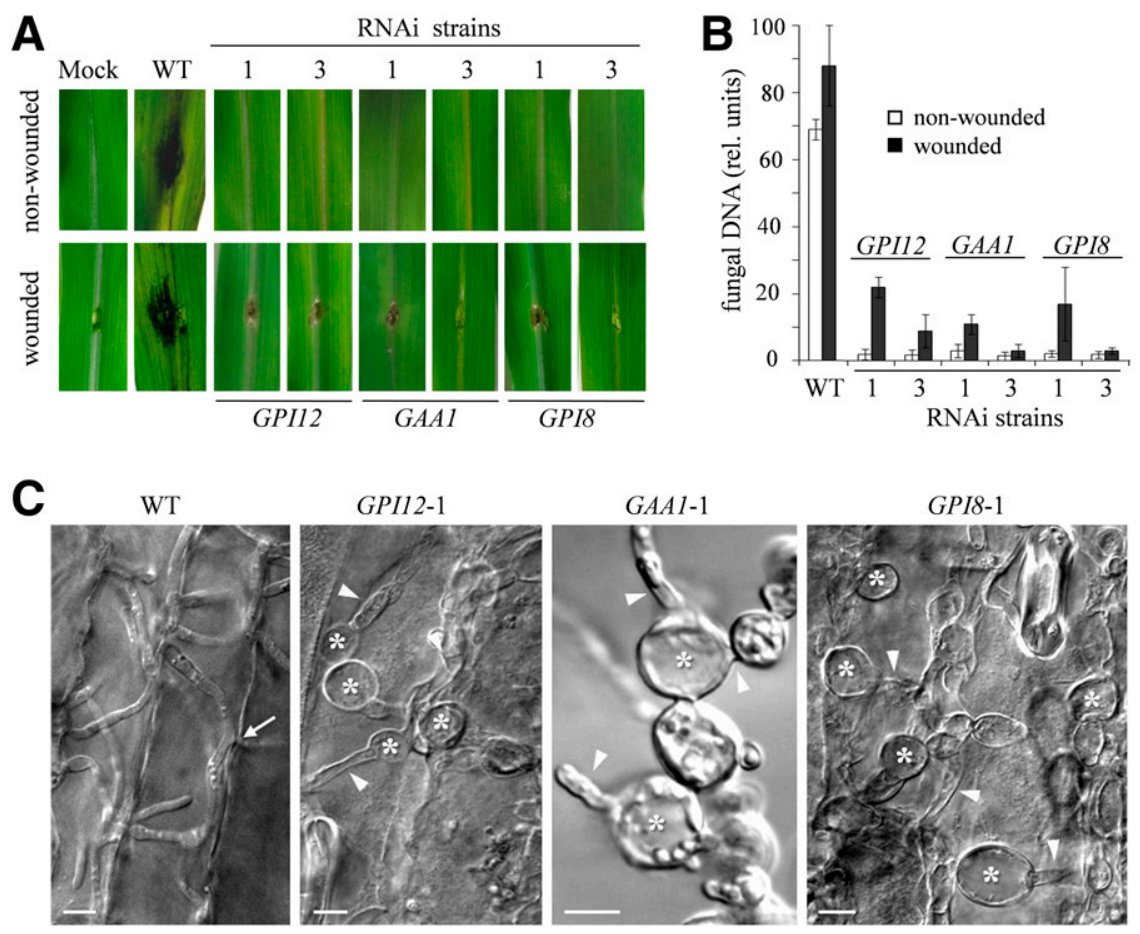

Fig. 8. GPI12-, GAA1-, and GPI8-RNA interference (RNAi) strains of Colletotrichum graminicola are unable to cause anthracnose disease symptoms and form severely distorted necrotrophic hyphae in maize leaves. A, Disease symptoms on nonwounded and wounded maize leaves after inoculation with the wild type (WT) and selected independent GPI12-, GAA1-, and GPI8-RNAi strains. RNAi strains 1 and 3 were employed in these infection assays. Mock-inoculated leaves were treated with $0.01 \%$ ( vol/vol) Tween 20 . Leaves were photographed 5 days after inoculation. B, Quantitative polymerase chain reaction-based quantification of fungal pathogenic development on intact (white bars) or wounded (black bars) maize leaves after inoculation with the strains used in A. Three biological repeats, with two technical repeats each, were analyzed; bars represent \pm standard deviations. C, Necrotrophic hyphae of a GPI12-, GAA1-, and GPI8-RNAi strains in maize leaves after wound inoculation. Hyphae show severe swellings (asterisks), connected by narrow hyphae (arrowheads). Arrow indicates a penetration point of a necrotrophic WT hypha in an anticlinal plant cell wall. Bars are $10 \mu \mathrm{m}$. 


\section{Measurement of conidiation rates, microscopy, and imaging.}

Conidiation rates were quantified as described (OliveiraGarcia and Deising 2013). Fungal strains were inoculated onto petri dishes $(9 \mathrm{~cm})$ containing OMA, and, after 14 days, cultures were washed on a rotary shaker with $10 \mathrm{ml} 0.01 \%$ ( vol/vol) Tween 20 for $10 \mathrm{~min}$. Conidia in these suspensions were counted in a Thoma chamber.

DIC microscopy was performed using a Nikon Eclipse 600 microscope (Nikon, Düsseldorf, Germany).

\section{Molecular phylogenetic analyses.}

Multiple sequence alignments and phylogenetic dendograms were calculated using ClustalW (Larkin et al. 2007) and MEGA 5 (Tamura et al. 2011). In ClustalW analyses minimum evolution algorithms employed 1,000 bootstrap replications. Sequences of the fungal GPI biosynthesis genes analyzed here were obtained from the National Center for Biotechnology Information.

Conserved protein domains were identified using the $\mathrm{Na}$ tional Center for Biotechnology Information (NCBI) Conserved Domain Database, the Predict Protein database, and the European Molecular Biology Laboratory (EMBL) InterPro database.

\section{Statistics.}

Calculations ( $t$ test, analysis of variance) were performed with the software XLSTAT version 2009.4.02 (Addinsoft, Witzenhausen, Germany).

\section{Accession numbers.}

Sequence data for genes of $C$. graminicola used in this article can be found in the GenBank/EMBL database under the following accession numbers.

GPI12 genes. Beauveria bassiana (EJP67273.1), Blumeria graminis (EPQ62736.1), C. graminicola (EFQ25317.1), C. gloeosporioides (EQB47646.1), C. higginsianum (CCF33957.1), Candida albicans (EEQ42199.1), Candida glabrata (XP_449479.1), Claviceps purpurea (CCE27514.1), F. fujikuroi (CCT73649.1), F. graminearum (XP_384272.1), F. oxysporum (EGU74772.1), Gaeumannomyces graminis (EJT81184.1), Magnaporthe oryzae (XP_003712526.1), N. crassa (XP_958505.2), Paracoccidioides brasiliensis (EEH49587.1), Talaromyces marneffei (XP_002146670.1), S. cerevisiae (EDN64221.1), Ustilago maydis, (XP_756449.1), Ustilago hordei (CCF54030.1).

GAAl genes. Beauveria bassiana (EJP61447.1), C. graminicola (EFQ30493.1), C. gloeosporioides (EQB54230.1), C. higginsianum (CCF39866.1), Candida albicans (XP_710522.1), Candida glabrata (XP_449300.1), F. fujikuroi (CCT67544.1), F. graminearum (ESU14293.1), F. oxysporum (EMT66877.1), F. solani (XP_003040723.1), Laccaria bicolor (XP_001875458.1), Magnaporthe oryzae (XP_003716396.1), N. crassa (XP_959789.1), Paracoccidioides brasiliensis (EEH22275.1), Talaromyces stipitatus (XP 002481458.1), S. arboricola (EJS42730.1), S. cerevisiae (EGA57795.1), Schizosaccharomyces pombe (NP_593498.1), Ustilago maydis (XP_762352.1), Ustilago hordei (CCF48763.1).

GPI8 genes. Beauveria bassiana (EJP69389.1), Blumeria graminis (EPQ66664.1), C. graminicola (EFQ31045.1), C. gloeosporioides (ELA35472.1), C. higginsianum (CCF33935.1), Candida albicans (EEQ42457.1), Candida glabrata (XP 449401.1), Claviceps purpurea (CCE31202.1), F. fujikuroi (CCT64293.1), F. oxysporum (ENH73817.1), F. solani (XP_389811.1), Laccaria bicolor (XP_001881167.1), Magnaporthe oryzae (XP_ 003713394.1), N. crassa (XP_962113.1), Paracoccidioides brasiliensis (EEH50609.1), Puccinia graminis (XP_003321138.2), Trichoderma virens (EHK21368.1), Talaromyces stipitatus (XP_ 002479217.1), S. arboricola arboricola (EJS42294.1), S. cerevisiae,
(EGA79476.1), Ustilago maydis (XP 761856.1), Ustilago hordei (CCF49395.1).

\section{ACKNOWLEDGMENTS}

The authors appreciate the highly skillful technical assistance of A. Beutel, D. Jany and E. Vollmer (Martin-Luther-University Halle-Wittenberg, Germany). We thank B. Tudzynski (Westfälische Wilhelms-Universität Münster, Germany) for providing plasmid pNR1 and S. Pöggeler and U. Kück (Ruhr-Universität Bochum, Germany) for providing plasmid pREDi. We are indebted to A. Mickel for help with microscopy and to J.-J. Krijger for providing unpublished data, helpful discussions, and for critically reading the manuscript. Funding by KWS Saat AG, Einbeck, Germany is gratefully acknowledged.

\section{LITERATURE CITED}

Abad, A., Fernández-Molina, J. V., Bikandi, J., Ramírez, A., Margareto, J., Sendino, J., Luis Hernando, F., Pontón, J., Garaizar, J., and Rementeria, A. 2010. What makes Aspergillus fumigatus a successful pathogen? Genes and molecules involved in invasive aspergillosis. Rev. Iberoam. Micol. 27:155-182.

Bastmeyer, M., Deising, H. B., and Bechinger, C. 2002. Force exertion in fungal infection. Annu. Rev. Biophys. Biomol. Struct. 31:321-341.

Bechinger, C., Giebel, K.-F., Schnell, M., Leiderer, P., Deising, H. B., and Bastmeyer, M. 1999. Optical measurements of invasive forces exerted by appressoria of a plant pathogenic fungus. Science 285:1896-1899.

Behr, M., Humbeck, K., Hause, G., Deising, H. B., and Wirsel, S. G. R. 2010. The hemibiotroph Colletotrichum graminicola locally induces photosynthetically active green islands but globally accelerates senescence on aging maize leaves. Mol. Plant-Microbe Interact. 23:879-892.

Benghezal, M., Benachour, A., Rusconi, S., Aebi, M., and Conzelmann, A. 1996. Yeast Gpi8p is essential for GPI anchor attachment onto proteins. EMBO J. 15:6575-6583.

Bergstrom, G. C., and Nicholson, R. L. 1999. The biology of corn anthracnose. Knowledge to exploit for improved management. Plant Dis 83:596-608.

Bowman, S. M., Piwowar, A., Al Dabbous, M., Vierula, J., and Free, S. J. 2006. Mutational analysis of the glycosylphosphatidylinositol (GPI) anchor pathway demonstrates that GPI-anchored proteins are required for cell wall biogenesis and normal hyphal growth in Neurospora crassa. Eukaryot. Cell 5:587-600.

Bruneau, J.-M., Magnin, T., Tagat, E., Legrand, R., Bernard, M., Diaquin, M., Fudali, C., and Latgé, J. P. 2001. Proteome analysis of Aspergillus fumigatus identifies glycosylphosphatidylinositolanchored proteins associated to the cell wall biosynthesis. Electrophoresis 22:2812-2823.

Caracuel, Z., Martínez-Rocha, A. L., Di Pietro, A., Madrid, M. P., and Roncero, M. I. 2005. Fusarium oxysporum gas1 encodes a putative $\beta$-1,3-glucanosyltransferase required for virulence on tomato plants. Mol. Plant-Microbe Interact. 18:1140-1147.

Caro, L. H., Tettelin, H., Vossen, J. H., Ram, A. F., Van den Ende, H., and Klis, F. M. 1997. In silicio identification glycosyl-phosphatidylinositolanchored plasma membrane and cell wall proteins of Saccharomyces cerevisiae. Yeast 13:1477-1489.

Castillo, L., Martinez, A. I., Garcera, A., Elorza, M. V., Valentin, E., and Sentandreu, R. 2003. Functional analysis of the cysteine residues and the repetitive sequence of Saccharomyces cerevisiae Pir4/Cis3: The repetitive sequence is needed for binding to the cell wall $\beta$-1,3-glucan Yeast 20:973-983.

de Medina-Redondo, M., Arnáiz-Pita, Y., Clavaud, C., Fontaine, T., del Rey, F., Latgé, J. P., and Vázquez de Aldana, C. R. 2010. $\beta(1,3)$ glucanosyl-transferase activity is essential for cell wall integrity and viability of Schizosaccharomyces pombe. PLoS One 5:e14046.

Ecker, M., Deutzmann, R., Lehle, L., Mrsa, V., and Tanner, W. 2006. Pir proteins of Saccharomyces cerevisiae are attached to $\beta$-1,3-glucan by a new protein-carbohydrate linkage. J. Biol. Chem. 281:11523-11529.

Eisenhaber, B., Maurer-Stroh, S., Novatchkova, M., Schneider, G., and Eisenhaber, F. 2003. Enzymes and auxiliary factors for GPI lipid anchor biosynthesis and post-translational transfer to proteins. BioEssays 25: 367-385.

Eisenhaber, B., Schneider, G., Wildpaner, M., and Eisenhaber, F. 2004. A sensitive predictor for potential GPI lipid modification sites in fungal protein sequences and its application to genome-wide studies for Aspergillus nidulans, Candida albicans, Neurospora crassa, Saccharomyces cerevisiae, and Schizosaccharomyces pombe. J. Mol. Biol. 337:243-253.

Eisenhaber, B., Eisenhaber, S., Kwang, T. Y., Grüber, G., and Eisenhaber, F. 2014. Transamidase subunit GAA1/GPAA1 is a M28 family 
metallo-peptide-synthetase that catalyzes the peptide bond formation between the substrate protein's omega-site and the GPI lipid anchor's phosphoethanolamine. Cell Cycle 13:1912-1917.

El Gueddari, N. E., Rauchhaus, U., Moerschbacher, B. M., and Deising, H. B. 2002. Developmentally regulated conversion of surface-exposed chitin to chitosan in cell walls of plant pathogenic fungi. New Phytol. 156:103-112.

Elorza, M. V., Rico, H., and Sentandreu, R. 1983. Calcofluor white alters the assembly of chitin fibrils in Saccharomyces cerevisiae and Candida albicans cells. J. Gen. Microbiol. 129:1577-1582.

Fesel, P. H., and Zuccaro, A. 2016. $\beta$-glucan: Crucial component of the fungal cell wall and elusive MAMP in plants. Fungal Genet. Biol. 90: 53-60.

Fraering, P., Imhof, I., Meyer, U., Strub, J. M., van Dorsselaer, A., Vionnet, C., and Conzelmann, A. 2001. The GPI transamidase complex of Saccharomyces cerevisiae contains Gaa1p, Gpi8p, and Gpi16p. Mol. Biol. Cell 12:3295-3306.

Grimme, S. J., Gao, X., Martin, P. S., Tu, K., Tcheperegine, S. E., Corrado, K., Farewell, A. E., Orlean, P., and Bi, E. 2004. Deficiencies in the endoplasmic reticulum (ER)-membrane protein GAB1p perturb transfer of glycosylphosphatidylinositol to proteins and cause perinuclear ERassociated actin bar formation. Mol. Biol. Cell 15:2758-2770.

Hamburger, D., Egerton, M., and Riezman, H. 1995. Yeast Gaa1p is required for attachment of a completed GPI anchor onto proteins. J. Cell Biol. 129:629-639.

Horbach, R., Graf, A., Weihmann, F., Antelo, L., Mathea, S., Liermann, J. C., Opatz, T., Thines, E., Aguirre, J., and Deising, H. B. 2009. Sfp-type $4^{\prime}$-phosphopantetheinyl transferase is indispensable for fungal pathogenicity. Plant Cell 21:3379-3396.

Horiuchi, H., Fujiwara, M., Yamashita, S., Ohta, A., and Takagi, M. 1999. Proliferation of intrahyphal hyphae caused by disruption of $\operatorname{csmA}$, which encodes a class $\mathrm{V}$ chitin synthase with a myosin motor-like domain in Aspergillus nidulans. J. Bacteriol. 181:3721-3729.

Janus, D., Hoff, B., Hofmann, E., and Kück, U. 2007. An efficient fungal RNA-silencing system using the DsRed reporter gene. Appl. Environ. Microbiol. 73:962-970.

Kang, X., Szallies, A., Rawer, M., Echner, H., and Duszenko, M. 2002. GPI anchor transamidase of Trypanosoma brucei: In vitro assay of the recombinant protein and VSG anchor exchange. J. Cell Sci. 115: 2529-2539.

Kim, J.-E., Lee, H.-J., Lee, J., Kim, K. W., Yun, S.-H., Shim, W.-B., and Lee, Y.-W. 2009. Gibberella zeae chitin synthase genes, GzCHS5 and $G z C H S 7$, are required for hyphal growth, perithecia formation, and pathogenicity. Curr. Genet. 55:449-459.

Koch, A., Kumar, N., Weber, L., Keller, H., Imani, J., and Kogel, K.-H. 2013. Host-induced gene silencing of cytochrome P450 lanosterol C14 $\alpha$-demethylase-encoding genes confers strong resistance to Fusarium species. Proc. Natl. Acad. Sci. U.S.A. 110:19324-19329.

Kollár, R., Petráková, E., Ashwell, G., Robbins, P. W., and Cabib, E. 1995. Architecture of the yeast cell wall. The linkage between chitin and $\beta(1 \rightarrow 3)$-glucan. J. Biol. Chem. 270:1170-1178.

Kollár, R., Reinhold, B. B., Petrakova, E., Yeh, H. J., Ashwell, G., Drgonova, J., Kapteyn, J. C., Klis, F. M., and Cabib, E. 1997. Architecture of the yeast cell wall. $\beta(1 \rightarrow 6)$-glucan interconnects mannoprotein, $\beta(1 \rightarrow 3)$-glucan, and chitin. J. Biol. Chem. 272:17762-17775.

Kopecká, M., and Gabriel, M. 1992. The influence of Congo red on the cell wall and $(1 \rightarrow 3)-\beta$-D-glucan microfibril biogenesis in Saccharomyces cerevisiae. Arch. Microbiol. 158:115-126.

Krijger, J.-J., Horbach, R., Behr, M., Schweizer, P., Deising, H. B., and Wirsel, S. G. R. 2008. The yeast signal sequence trap identifies secreted proteins of the hemibiotrophic corn pathogen Colletotrichum graminicola. Mol. Plant-Microbe Interact. 21:1325-1336.

Krijger, J.-J., Thon, M. R., Deising, H. B., and Wirsel, S. G. R. 2014 Compositions of fungal secretomes indicate a greater impact of phylogenetic history than lifestyle adaptation. BMC Genomics 15: 722.

Larkin, M. A., Blackshields, G., Brown, N. P., Chenna, R., McGettigan, P. A., McWilliam, H., Valentin, F., Wallace, I. M., Wilm, A., Lopez, R., Thompson, J. D., Gibson, T. J., and Higgins, D. G. 2007. Clustal W and Clustal X version 2.0. Bioinformatics 23:2947-2948.

Latgé, J. P. 2007. The cell wall: A carbohydrate armour for the fungal cell. Mol. Microbiol. 66:279-290.

Leach, J., Lang, B. R., and Yoder, O. C. 1982. Methods for selection of mutants and in vitro culture of Cochliobolus heterostrophus. J. Gen. Microbiol. 128:1719-1729.

Levin, D. E. 2011. Regulation of cell wall biogenesis in Saccharomyces cerevisiae: The cell wall integrity signaling pathway. Genetics 189: 1145-1175.
Li, H., Zhou, H., Luo, Y., Ouyang, H., Hu, H., and Jin, C. 2007. Glycosylphosphatidylinositol (GPI) anchor is required in Aspergillus fumigatus for morphogenesis and virulence. Mol. Microbiol. 64: 1014-1027.

Malonek, S., Rojas, M. C., Hedden, P., Gaskin, P., Hopkins, P., and Tudzynski, B. 2004. The NADPH-cytochrome $\mathrm{P} 450$ reductase gene from Gibberella fujikuroi is essential for gibberellin biosynthesis. J. Biol. Chem. 279:25075-25084.

Mendgen, K., and Deising, H. 1993. Infection structures of fungal plant pathogens-A cytological and physiological evaluation. New Phytol. 124:193-213.

Mouyna, I., Morelle, W., Vai, M., Monod, M., Léchenne, B., Fontaine, T., Beauvais, A., Sarfati, J., Prévost, M. C., Henry, C., and Latgé, J. P. 2005. Deletion of GEL2 encoding for a $\beta(1 \rightarrow 3)$ glucanosyltransferase affects morphogenesis and virulence in Aspergillus fumigatus. Mol. Microbiol. 56:1675-1688.

Nowara, D., Gay, A., Lacomme, C., Shaw, J., Ridout, C., Douchkov, D., Hensel, G., Kumlehn, J., and Schweizer, P. 2010. HIGS: Host-induced gene silencing in the obligate biotrophic fungal pathogen Blumeria graminis. Plant Cell 22:3130-3141.

O'Connell, R. J., Thon, M. R., Hacquard, S., Amyotte, S. G., Kleemann, J., Torres, M. F., Damm, U., Buiate, E. A., Epstein, L., Alkan, N., Altmuller, J., Alvarado-Balderrama, L., Bauser, C. A., Becker, C., Birren, B. W., Chen, Z., Choi, J., Crouch, J. A., Duvick, J. P., Farman, M. A., Gan, P., Heiman, D., Henrissat, B., Howard, R. J., Kabbage, M., Koch, C., Kracher, B., Kubo, Y., Law, A. D., Lebrun, M. H., Lee, Y. H., Miyara, I., Moore, N., Neumann, U., Nordstrom, K., Panaccione, D. G., Panstruga, R., Place, M., Proctor, R. H., Prusky, D., Rech, G., Reinhardt, R., Rollins, J. A., Rounsley, S., Schardl, C. L., Schwartz, D. C., Shenoy, N., Shirasu, K., Sikhakolli, U. R., Stuber, K., Sukno, S. A., Sweigard, J. A., Takano, Y., Takahara, H., Trail, F., van der Does, H. C., Voll, L. M., Will, I., Young, S., Zeng, Q., Zhang, J., Zhou, S., Dickman, M. B., SchulzeLefert, P., Ver Loren van Themaat, E., Ma, L. J., and Vaillancourt, L. J. 2012. Lifestyle transitions in plant pathogenic Colletotrichum fungi deciphered by genome and transcriptome analyses. Nat. Genet. 44: 1060-1065.

Oliveira-Garcia, E., and Deising, H. B. 2013. Infection structure-specific expression of $\beta$-1,3-glucan synthase is essential for pathogenicity of Colletotrichum graminicola and evasion of $\beta$-glucan-triggered immunity. Plant Cell 25:2356-2378.

Oliveira-Garcia, E., and Deising, H. B. 2016. Attenuation of PAMPtriggered immunity in maize requires down-regulation of the key $\beta$-1,6-glucan synthesis genes KRE5 and KRE6 in biotrophic hyphae of Colletotrichum graminicola. Plant J. 87:355-375.

Piłsyk, S., and Paszewski, A. 2009. The Aspergillus nidulans pigP gene encodes a subunit of GPI- $N$-acetylglucosaminyltransferase which influences filamentation and protein secretion. Curr. Genet. 55:301-309.

Pittet, M., and Conzelmann, A. 2007. Biosynthesis and function of GPI proteins in the yeast Saccharomyces cerevisiae. Biochim. Biophys. Acta 1771:405-420.

Ram, A. F. J., and Klis, F. M. 2006. Identification of fungal cell wall mutants using susceptibility assays based on Calcofluor white and Congo red. Nat. Protoc. 1:2253-2256.

Richard, M. L., and Plaine, A. 2007. Comprehensive analysis of glycosylphosphatidylinositol-anchored proteins in Candida albicans. Eukaryot. Cell 6:119-133.

Richard, M., Ibata-Ombetta, S., Dromer, F., Bordon-Pallier, F., Jouault, T., and Gaillardin, C. 2002. Complete glycosylphosphatidylinositol anchors are required in Candida albicans for full morphogenesis, virulence and resistance to macrophages. Mol. Microbiol. 44:841-853.

Rittenour, W. R., and Harris, S. D. 2013. Glycosylphosphatidylinositolanchored proteins in Fusarium graminearum: Inventory, variability, and virulence. PLoS One 8:e81603.

Rovenich, H., Zuccaro, A., and Thomma, B. P. H. J. 2016. Tansley insight: Convergent evolution of filamentous microbes towards evasion of glycan-triggered immunity. New Phytol. Published online. doi: 10.1111/nph.14064

Siafakas, A. R., Wright, L. C., Sorrell, T. C., and Djordjevic, J. T. 2006. Lipid rafts in Cryptococcus neoformans concentrate the virulence determinants phospholipase $\mathrm{B} 1$ and $\mathrm{Cu} / \mathrm{Zn}$ superoxide dismutase. Eukaryot. Cell 5:488-498.

Silar, P. 1995. Two new easy to use vectors for transformations. Fungal Genet. Newsl. 42:73.

Smith, T. K., Cottaz, S., Brimacombe, J. S., and Ferguson, M. A. J. 1996 Substrate specificity of the dolichol phosphate mannose:glucosaminyl phosphatidylinositol $\alpha 1-4$-mannosyltransferase of the glycosylphosphatidylinositol biosynthetic pathway of African trypanosomes. J. Biol. Chem. 271:6476-6482. 
Smits, G. J., Kapteyn, J. C., van den Ende, H., and Klis, F. M. 1999. Cell wall dynamics in yeast. Curr. Opin. Microbiol. 2:348-352.

Tamura, K., Peterson, D., Peterson, N., Stecher, G., Nei, M., and Kumar, S. 2011. MEGA5: Molecular evolutionary genetics analysis using maximum likelihood, evolutionary distance, and maximum parsimony methods. Mol. Biol. Evol. 28:2731-2739.

Umemura, M., Okamoto, M., Nakayama, K.-i., Sagane, K., Tsukahara, K., Hata, K., and Jigami, Y. 2003. GWT1 gene is required for inositol acylation of glycosylphosphatidylinositol anchors in yeast. J. Biol. Chem. 278:23639-23647.

Vainauskas, S., Maeda, Y., Kurniawan, H., Kinoshita, T., and Menon, A. K. 2002. Structural requirements for the recruitment of Gaa1 into a functional glycosylphosphatidylinositol transamidase complex. J. Biol. Chem. 277:30535-30542.

Watanabe, R., Ohishi, K., Maeda, Y., Nakamura, N., and Kinoshita, T. 1999. Mammalian PIG-L and its yeast homologue Gpi12p are $N$-acetylglucosaminylphosphatidylinositol de- $N$-acetylases essential in glycosylphosphatidylinositol biosynthesis. Biochem. J. 339:185-192.

Werner, S., Sugui, J. A., Steinberg, G., and Deising, H. B. 2007. A chitin synthase with a myosin-like motor domain is essential for hyphal growth, appressorium differentiation and pathogenicity of the maize anthracnose fungus Colletotrichum graminicola. Mol. Plant-Microbe Interact. 20:1555-1567.

Wilson, R. A., and Talbot, N. J. 2009. Under pressure: Investigating the biology of plant infection by Magnaporthe oryzae. Nat. Rev. Microbiol. 7:185-195.

Yan, J., Du, T., Zhao, W., Hartmann, T., Lu, H., Lü, Y., Ouyang, H., Jiang, X., Sun, L., and Jin, C. 2013. Transcriptome and biochemical analysis reveals that suppression of GPI-anchor synthesis leads to autophagy and possible necroptosis in Aspergillus fumigatus. PLoS One 8:e59013.

Yelton, M. M., Hamer, J. E., and Timberlake, W. E. 1984. Transformation of Aspergillus nidulans by using a $\operatorname{trpC}$ plasmid. Proc. Natl. Acad. Sci. U.S.A. 81:1470-1474.

Yu, S., Guo, Z., Johnson, C., Gu, G., and Wu, Q. 2013. Recent progress in synthetic and biological studies of GPI anchors and GPI-anchored proteins. Curr. Opin. Chem. Biol. 17:1006-1013.

Zhang, S., Xia, Y., and Keyhani, N. O. 2011. Contribution of the gas1 gene of the entomopathogenic fungus Beauveria bassiana, encoding a putative glycosylphosphatidylinositol-anchored $\beta$-1,3-glucanosyltransferase, to conidial thermotolerance and virulence. Appl. Environ. Microbiol. 77: 2676-2684.

\section{AUTHOR RECOMMENDED INTERNET RESOURCES}

ClustalW server: http://embnet.vital-it.ch/software/ClustalW.html EMBL InterPro database: http://www.ebi.ac.uk/interpro MEGA software: www.megasoftware.net

NCBI Colletotrichum graminicola genome page:

http://www.ncbi.nlm.nih.gov/genome/?term=Glomerella+graminicola NCBI Conserved Domain Database: http://www.ncbi.nlm.nih.gov/cdd NCBI website: http://www.ncbi.nlm.nih.gov

Predict Protein database: https://www.predictprotein.org 